\title{
Nanotechnology to the Rescue: Treatment Perspective for the Immune Dysregulation Observed in COVID-19
}

\section{OPEN ACCESS}

Edited by:

Hitendra S. Chand,

Florida International University,

United States

Reviewed by:

Dinesh Devadoss,

Florida International University,

United States

Ibrahim C. Haznedaroglu,

Hacettepe University Hospital, Turkey

*Correspondence:

Angela E. Peter

angelapeter.728@gmail.com

Specialty section:

This article was submitted to Biomedical Nanotechnology,

a section of the journal

Frontiers in Nanotechnology

Received: 19 December 2020 Accepted: 05 March 2021

Published: 31 March 2021

Citation:

Peter AE, Sandeep BV, Rao BG and Kalpana VL (2021) Nanotechnology to the Rescue: Treatment Perspective for the Immune Dysregulation Observed in COVID-19.

Front. Nanotechnol. 3:644023. doi: 10.3389/fnano.2021.644023

\begin{abstract}
Angela E. Peter ${ }^{1 *}$, B. V. Sandeep ${ }^{1}$, B. Ganga Rao ${ }^{2}$ and V. Lakshmi Kalpana ${ }^{3}$
${ }^{1}$ Department of Biotechnology, College of Science \& Technology, Andhra University, Visakhapatnam, India, ${ }^{2}$ Andhra University College of Pharmaceutical Sciences, Andhra University, Visakhapatnam, India, ${ }^{3}$ Department of Human Genetics, College of Science \& Technology, Andhra University, Visakhapatnam, India
\end{abstract}

The study of the use of nanotechnology for drug delivery has been extensive. Nanomedical approaches for therapeutics; drug delivery in particular is superior to conventional methods in that it allows for controlled targeted delivery and release, higher stability, extended circulation time, minimal side-effects, and improved pharmacokinetic clearance (of the drug) form the body, to name a few. The magnitude of COVID-19, the current ongoing pandemic has been severe; it has caused widespread the loss of human life. In individuals with severe COVID-19, immune dysregulation and a rampant state of hyperinflammation is observed. This kind of an immunopathological response is detrimental and results in rapid disease progression, development of secondary infections, sepsis and can be fatal. Several studies have pin-pointed the reason for this immune dysregulation; deviations in the signaling pathways involved in the mediation and control of immune responses. In severe COVID-19 patients, many signaling cascades including JAK/STAT, NF-кB, MAPK/ERK, TGF beta, VEGF, and Notch signaling were found to be either upregulated or inactivated. Targeting these aberrant signaling pathways in conjunction with antiviral therapy will effectuate mitigation of the hyperinflammation, hypercytokinemia, and promote faster recovery. The science of the use of nanocarriers as delivery agents to modulate these signaling pathways is not new; it has already been explored for other inflammatory diseases and in particular, cancer therapy. Numerous studies have evaluated the efficacy and potential of nanomedical approaches to modulate these signaling pathways and have been met with positive results. A treatment regime, that includes nanotherapeutics and antiviral therapies will prove effective and holds great promise for the successful treatment of COVID-19. In this article, we review different nanomedical approaches already studied for targeting aberrant signaling pathways, the host immune response to SARS-CoV-2, immunopathology and the dysregulated signaling pathways observed in severe COVID-19 and the current treatment methods in use for targeting signaling cascades in COVID-19. We then conclude by suggesting that the use of nanomedical drug delivery systems for targeting signaling pathways can be extended to effectively target the aberrant signaling pathways in COVID-19 for best treatment results.

Keywords: nanomedicine, COVID-19, SARS-CoV-2, immune dysfunction, signaling pathways 


\section{INTRODUCTION}

The current and ongoing outbreak of the novel coronavirus SARS-CoV-2 infection; COVID-19 began a year back, in December 2019 (Li H. et al., 2020; Velavan and Meyer, 2020). The disease spread rapidly across the globe, affecting 223 countries and causing about 2,656,822 deaths to date (World Health Organization, 2020b,f). There has been no respite; currently, more COVID-19 cases have been reported in the past 4 weeks than in the first 6 months of the pandemic, which could be attributed to the second wave of COVID-19 (World Health Organization, 2020g). With the earnest and vigorous efforts by the scientific community globally, seven different vaccines have been rolled out in countries (World Health Organization, 2020d). Seventy three vaccines are in the clinical development stage and 182 are in the pre-clinical development phase (World Health Organization, 2020c). While the disease presentation of COVID-19 is similar to influenza infections, the mortality for COVID-19 is significantly higher; $3-4 \%$ as compared to below $0.1 \%$ for influenza infections (World Health Organization, 2020a). The reason for this high fatality lies in the fact that the severity of COVID-19 disease is not only due to SARSCoV-2 infection, but also due to the complex host immune response. Patients with severe COVID-19 disease exhibit immune dysregulation; a hyper-activated/exhausted immune response associated with hyperinflammation and sustained cytokine production/hypercytokinemia (Giamarellos-Bourboulis et al., 2020; Praveen et al., 2020; Tahaghoghi-Hajghorbani et al., 2020; Tay et al., 2020; Varchetta et al., 2020; Wei et al., 2020). As a result, such patients exhibit organ injury, organ failure progressing into ARDS, secondary infections, sepsis, septic shock, and multiple organ failure leading to mortality (Li D. et al., 2020; Pedersen and Ho, 2020; Qin et al., 2020). Additionally, patients with co-morbidities (diabetes, cancer, liver disease, CKD, COPD, CVA, CVD, hypertension; especially the elderly) and immunocompromised individuals are more susceptible to severe COVID-19 disease and this patient group is associated with increased complications and higher mortality (Fung and Babik, 2020; Gao et al., 2020; Guan et al., 2020; Harrison et al., 2020; Luo L. et al., 2020; Mehraeen et al., 2020; Posso et al., 2020; Singh and Misra, 2020).

Both inflammatory responses and immune responses are crucial and a perquisite for the targeting and elimination of SARS-CoV-2 and consequent disease. However, in the severe COVID-19 cases, immune-mediated injury and acute inflammation drive the immunopathogenesis that causes a quick deterioration and death. Multiple signaling pathways are responsible for powering this sustained cytokine production and acute inflammation and are implicated in the destructive immunopathogenesis observed in COVID-19. Targeting these overactivated signaling pathways which are at the root of the state of hyperinflammation will facilitate suitable immunomodulatory intervention for maximum therapeutic effects (Merad and Martin, 2020; Song et al., 2020; Yarmohammadi et al., 2020). Nanomedicine presents tremendous potential, with advantages like improved safety, efficacy, targeting, toxicity profiles, patient compliance and increase in the intracellular uptake of the drug
(Ventola, 2012). A novel and an efficient strategy would involve the use of nanomedical approaches to target the signal cascades to curb the hyperinflammation and hypercytokinemia and thus mitigate the immunopathogenesis observed in COVID-19.

\section{NANOMEDICINE}

The application of nanotechnology; nanoscale materials to the field of health sciences and medicine for the purpose of diagnosis, monitoring, control, prevention, and treatment of disease is nanomedicine (Hawthorne et al., 2017; Tekade et al., 2017). A nanoscale material may be a natural, incidental or a manufactured material comprising of particles, either in an unbound state or as an aggregate, wherein the size range of one or more external dimensions is between 1 and $100 \mathrm{~nm}$ for $\geq 50 \%$ (threshold between 1 and 50\%) of the particles, according to the number size distribution that encapsulates a therapeutic compound (Arms et al., 2018; Soares et al., 2018). Some of the nanoscale systems that can be employed for drug delivery are lipid-based vehicles, polymer-based delivery systems, metal nanoparticles, nanoshells, and non-injectable nanovectors (Riehemann et al., 2009). Liposomes, solid lipid nanoparticles (SLN) and nanostructured lipid carriers (NLC) are the lipid-based nanoparticles that facilitate the transport of both hydrophobic and hydrophilic molecules, controlled drug release with a very low or no toxicity (García-Pinel et al., 2019). In polymer-based delivery systems, the polymer may be of natural origin like chitosan, starch, alginate, cellulose; biosynthesized, poly- $\beta$-hydroxybutyrate (PHB) or chemically synthesized materials like polylactic acid (PLA), polyurethane, poly(lactic-glycolic acid) (PLGA), polymethyl methacrylate resin (PMMA). Some of the main advantages of these of these polymer-based delivery systems include high biological safety, good biodegradability, and safe delivery of the drug (Han et al., 2018). Metal nanoparticles are made up of pure metals; gold, platinum, silver, titanium, zinc, cerium, iron, and thallium or their compounds (oxides, hydroxides, sulfides, phosphates, fluorides, and chlorides) (Piñón-Segundo et al., 2013). The noble metals are known for non-toxicity and antimicrobial properties and the metal oxide nanoparticles have a high stability, ease of preparation and easy fictionalization (Nikolova and Chavali, 2020; Yaqoob et al., 2020). Nanoshells consist of spherical dielectric nanoparticles surrounded by an ultrathin conductive metal layer that is activated by tunable optical resistance. Nanoshells tagged with specific antibodies are useful in the treatment of immunological disease efficiently. Nanovectors (first, second, and third generation) are nanoparticles that transport and deliver more than one bioactive molecule/therapeutic agent. Non-injectable nanovectors offer a convenient method for delivery of drugs via oral route. In recent years the use of nanomedical technology has revolutionized healthcare strategies and is envisioned to have a great impact in offering better drug delivery and gene therapy, thus gaining an increasing research interest in the current medical sector of the modern world (Riehemann et al., 2009; Muthuraman et al., 2018; Prasad et al., 2018). 


\section{NANOMEDICINE: TARGETING SIGNALING PATHWAYS}

Signaling transduction pathways are a chain of reactions that involve a complex ballet of molecules interacting and stimulating surrounding proteins, lipids and ions that culminate in the transmission of signals from the cell surface to a variety of intracellular targets including transcription factors. These molecular circuits detect, amplify, and integrate diverse external signals that result in changes in enzyme activity or ion-channel activity as a consequence of which induction of gene expression, cytoskeletal reorganization and modulation of differentiation occurs (Cooper, 2000; Berg et al., 2002b; Svoboda and Reenstra, 2002). Some of the important signaling pathways are the JAK/STAT, TLR, NF-кB, PI3K/AkT, mTOR, MAPK/ERK, AMPK, TGF beta, VEGF, and Notch signaling cascades. As all these signaling pathways are very complex, they occasionally fail, causing a disruption in the normal cellular function and ultimately leads to the establishment of a pathological state in the body. Defects in the signaling pathways are the basis of many diseases and are thus the target for drug therapies (MoraGarcia and Sakamoto, 1999; Berg et al., 2002a; Halazy, 2003). Nanomedicine presents a novel, safe and effective approach to target these aberrant pathways. The use of nanoparticles to target errant signal cascades and the specific transcriptional factors involved has been explored for treatment of inflammatory diseases and cancer therapy (Tiwari et al., 2018).

\section{Nanomedical Targeting of the JAK/STAT Signaling Pathway}

The Janus kinase-signal transducer and activator of transcription (JAK/STAT) pathway has an important role to play in transferring signals from the receptors on the surface of cell membrane to the nucleus. This pathway is crucial for the production of a range of growth factors and cytokines, leading to critical events in the body; the development of the immune system, organismal growth, hematopoiesis, stem cell maintenance, and mammary gland development. The JAK/STAT pathway is involved in proliferation, differentiation, migration, apoptosis, and cell survival; its outcome dependent on the signal, tissue, and cellular context (Harrison, 2012; Seif et al., 2017). Several studies have been carried out; in vitro and in vivo for targeting STAT using nanoparticles, liposomes and micelles (Ashrafizadeh et al., 2019). Reduced expression of STAT3 was achieved using gold nanoparticles as carriers for STAT3 siRNA and imatinib, both in vitro and in vivo (Labala et al., 2017). PEIPLGA-FITC nanoparticles with siRNA targeting STAT3 brought about the downregulation of IL-6 in Balb/c mice (Das et al., 2014). In ovarian cancer cell lines $\mathrm{A} 2780 \mathrm{CP}$ and A2780ss, liposome carriers of shRNA against STAT3 brought about an increase in apoptosis and inhibited cell proliferation (Jiang et al., 2013). Downregulation of STAT3 was also achieved by using micelle nanoparticles for the delivery of STAT3 siRNA in an in vivo study in mice with tumor-associated DCs (Luo et al., 2015). Large unilamellar vesicle (LUV) nanoparticles with PEGylated particle containing WHI-P131 (Jak3 tyrosine kinase inhibitor) was prepared and exhibited significant efficacy in targeting JAK3/STAT pathway in vitro and in vivo (Uckun et al., 2010).

\section{Nanomedical Targeting of the TLR Signaling Pathway}

Toll-like receptor (TLR) signaling has a very important part to play in innate immune responses with respect to pathogens. The toll-like receptors are responsible for recognition of pathogen-associated molecular patterns of different microbes. Subsequent signaling drives the recruitment of specific adaptor molecules that leads to the activation of transcription factors NF- $\mathrm{B}$ and IRFs that direct the course of the innate immune response (Kawasaki and Kawai, 2014). TLR nano-inhibitors are in the preclinical stage of investigation (Gao et al., 2017). Synthesized glycol-split non-anticoagulant heparin with Derythro-sphingosine graft nanoparticles, with the ability to selfassemble into NAHNP were effective in suppressing the LPSinduced MyD88-dependent NF- $\kappa \mathrm{B}$ activation that resulted in the inhibition of subsequent cytokines production in mouse macrophages (Babazada et al., 2014). Another nanodevice, highdensity lipoprotein (HDL)-like nanoparticles with a gold NP core and a HDL coating was able to inhibit TLR4 signaling induced by different sources of LPS and Gram-negative bacteria in human cell lines and PBMC (Foit and Thaxton, 2016). Gold nanoparticles designed with a glycolipid mimicking lipid A binding to CD14 and the TLR-MD2 pocket successfully inhibited the activation of TLR4-MD2 induced by LPS in murine and human cells (Lavado et al., 2014). An anti-inflammatory peptide (P12)-gold nanoparticle hybrid developed exhibited inhibitory effects on TLR2, TLR3, TLR5, and both arms of TLR4 (MyD88-dependent NF- $\kappa \mathrm{B}$ and TRIF-dependent IRF3 activation) signaling pathways (Yang et al., 2011, 2013, 2015, 2016).

\section{Nanomedical Targeting of the NF-кB Signaling Pathway}

Nuclear factor- $\kappa \mathrm{B}$ is a family of transcription factors that are associated with vital functions; regulation of inflammation, innate and adaptive immune responses and development, cell survival and proliferation (O'Dea and Hoffmann, 2009). In a study carried out poly lactide co-glycolide (PLGA) nanoparticles conjugated with anti-CD44 and encapsulating NF-кB inhibitor parthenolide (PTL) were designed and tested for bioactivity in vitro in leukemic cell lines Kasumi-1, KG-1a, and THP-1. Treatment with prepared PTL nanoparticles induced a marked reduction $(40 \%)$ in proliferation when compared to treatment with free PTL (Ruttala and Ko, 2015). In another study, mannosylated nanoparticles used for the delivery of siRNA to ex vivo macrophages in culture could successfully modulate NF- $\mathrm{B}$ signaling (Darwish et al., 2019). Curcumin-loaded nanospheres was shown to inhibit NF-кB activity in metastatic LNCaP, PC3, and DU145 prostate cancer cell lines (Mukerjee and Vishwanatha, 2009; Yallapu et al., 2010; Maher et al., 2011). The sustained release of paclitaxel and curcumin from PTXloaded albumin nanoparticles (APN) prepared and encapsulated in PEGylated hybrid liposomes containing CUR (CL-APN) via 
a thin-film hydration technique occurred in sequential kinetics; curcumin downregulated nuclear factor NF-kB and enhanced the therapeutic efficacy of paclitaxel (Mimeault and Batra, 2011; Ortega et al., 2016).

\section{Nanomedical Targeting of the PI3K/AkT Signaling Pathway}

An intracellular pathway of great importance, the phosphatidylinositol-4,5-bisphosphate 3-kinase/protein kinase $\mathrm{B}$ (PI3K/AkT) pathway is associated with essential cellular functions like cellular quiescence, proliferation, longevity, and cancer (Xie et al., 2019). Nanomedical approaches have provided interesting avenues for targeting this pathway; some of which are in the pre-clinical stage and others are at the clinical stages (Sharma et al., 2019). A PI3K $\alpha$ inhibitor BYL719 was encapsulated into P-selectin-targeted nanoparticles and studies were carried out to evaluate its efficacy and specificity in mouse models of head and neck squamous cell carcinomas. Successful targeting resulted in reduction of tumor growth and additionally, the acute and chronic metabolic side effects normally observed with BYL719 treatment were effectively abrogated with the nanotechnological treatment approach (Mizrachi et al., 2017). In another study, nanoparticles were designed and prepared with the PI3K/mTOR dual inhibitor, BEZ235 effectively brought about the inhibition of the PI3K/mTOR pathway in in vitro and in vivo studies in non-Hodgkin's lymphoma models (Au et al., 2020). $\mathrm{N}$-(4-hydroxyphenyl)4-hydroxy-2-quinolone-3-carboxamide,

a $\mathrm{PI} 3 \mathrm{~K} \alpha$ inhibitor was conjugated with gold nanorods and the effect of these nanoparticles was explored on MCF-7 breast cancer cells. Gene expression of several transcription factors responsible for cell growth and proliferation, apoptotic pathways, and cell cycle arrest was significantly effected by the treatment with the prepared nanocomplex (Mahmoud et al., 2020). PLGA nanoparticles synthesized with inhibitor GANT61 and curcumin effectively mediated PI3K/AkT inhibition in heterogeneous breast cancer cell line MCF-7 (Borah et al., 2020).

\section{Nanomedical Targeting of the mTOR Signaling Pathway}

The mammalian target of rapamycin (mTOR) is a wellconserved serine/threonine kinase. The mTOR signaling pathway is responsible for sensing and integrating diverse environmental cues for the regulation of organismal growth and homeostasis (Laplante and Sabatini, 2012a,b). Modulation of the mTOR signaling by the use of nanomedical approaches is still in the pre-clinical stage. There have been several studies that have shown that this approach increases the bioavailability and efficacy; however the mechanism of mTOR activity modulation and mode of action is still to be established (Lunova et al., 2019). Polystyrene nanoparticles with amino groups act as inhibitors of mTOR signaling consequently inducing G2 cellcycle arrest and inhibition of proliferation in three leukemia cell lines (Loos et al., 2014). Inhibition of mTOR in podocytes was observed on treatment with titanium dioxide nanoparticles thus causing autophagy and protecting against oxidative stress on the cell proliferation (Zhang et al., 2016). In a mouse model of Alzheimer's disease, functionalized single-walled carbon nanotubes efficiently reversed the abnormal activation of mTOR signaling thus alleviating the autophagic/lysosomal defects in primary glia (Xue et al., 2014). Superior anti-tumor activity was observed on employing nanoparticles for co-delivery of rapamycin and paclitaxel by targeting the aberrant PI3K/Akt/ mTOR pathway in vitro in MDA-MB-468 and MCF-7 breast cancer cells (Blanco et al., 2014).

\section{Nanomedical Targeting of the MAPK/ERK Signaling Pathway}

The mitogen-activated protein kinase/extracellular-signal regulated kinase $1 / 2$ (MAPK/ERK) are essential signaling cascades that are involved in the regulation of diverse cellular processes, including proliferation, differentiation, apoptosis, and stress responses (Guo et al., 2020). The use of nanotechnology to target the MAPK/ERK signaling pathways is still in the development stages; while there are significant number of studies that are promising, clinical efficacy is yet to be demonstrated (Inamdar et al., 2010). Engineered nanoparticles of a unique hexadentate-polyD,L-lactic acid-co-glycolic acid polymer conjugated chemically to a selective MAPK inhibitor PD98059 were administered to melanoma-bearing mice in a study. Effective targeting of MAPK signaling by the nanoparticles results in an inhibition of proliferation of the melanoma and lung carcinoma cells and induction of apoptosis in vitro and inhibition of tumor growth in vivo (Basu et al., 2009). In murine B16F10 melanoma cells, two injections of a LPH (liposome-polycation-hyaluronic acid) nanoparticle designed with miRNA-34a brought about a downregulation of MAPK pathway (Chen et al., 2010). Luminescent ruthenium-modified selenium nanoparticles (Ru-SeNPs) effectively suppressed the ERK signaling pathway in a study carried out on HepG2 cells (Sun et al., 2013). A combination of sorafenib and nanoliposomal ceramide was found to be more potent in targeting MAPK and PI3K/Akt pathways than either agent alone in a study carried out in UACC 903, 1205 Lu, FF2441 and MDA-MB-231 cells (Tran et al., 2008).

\section{Nanomedical Targeting of the AMPK Signaling Pathway}

An evolutionary conserved serine/threonine kinase, the $5^{\prime}$ - adenosine monophosphate (AMP)-activated protein kinase $(\mathrm{AMPK})$ regulates diverse metabolic and physiological processes. AMPK signaling is involved in regulating growth and reprogramming metabolism, and has been recently connected to cellular processes including autophagy and cell polarity (Mihaylova and Shaw, 2011; Jeon, 2016). Nanoparticle delivery systems facilitate the target drugs to exert a significant modulatory effect on AMPK signaling. Studies employing bismuth nanoparticles, iron oxide nanoparticles, micellar nanoparticles, and cationic polystyrene nanoparticles established that the AMPK signaling could be targeted and modulated effectively with nanotechnological approach (Khan et al., 2012; Chiu et al., 2015; Liu et al., 2018; Hui-Hui et al., 2019). 


\section{Nanomedical Targeting of the TGF Beta Signaling Pathway}

The transforming growth factor $\beta$ superfamily are secreted ligands that are responsible for the regulation of diverse developmental and physiological functions (Bierie and Moses, 2010; Wrana, 2013). In a melanoma model of tumor studied using B16F10l cells, both nanoparticle-based delivery systems; lipid-calcium-phosphate (LCP) nanoparticle (NP) and liposomeprotamine-hyaluronic acid (LPH) NP for the delivery of LCP vaccine and siRNA, respectively, were capable of downregulating the TGF- $\beta$ signaling (Xu et al., 2014). In another study, polyethyleneimine/polyethylene glycol-conjugated MSNPs loaded with TGF- $\beta$ inhibitor LY364947 that were designed mediated systemic biodistribution and retention at the tumor site and effective targeting of TGF- $\beta$ signaling in in vitro and in vivo models of pancreatic ductal adenocarcinoma (Meng et al., 2013). In another in vivo study, a synergistic approach using a nanoparticle drug delivery system that included the TGF- $\beta$ signaling pathway inhibitor LY364947 was found to enhance both tumor penetration and cancer stem cell clearance because of effective inhibition of the TGF- $\beta$ signaling pathway (Lu et al., 2016). The immunosuppressive TGF- $\beta 1$ signaling could be attenuated by the use of gold nanoparticles, as exhibited by a study carried out on in an in vivo model of murine bladder tumor 2 cells in syngeneic C3H/HeN mice (Tsai et al., 2013).

\section{Nanomedical Targeting of the VEGF Signaling Pathway}

The vascular endothelial growth factor (VEGF) is a family of soluble growth factors; VEGF-A/VEGF, VEGF-B, VEGF-C, VEGF-D, and placenta growth factor (PGF) that exert salient biological functions through interactions with transmembrane tyrosine kinase receptors, present on cell surfaces (Frumovitz and Sood, 2007; Stacker and Achen, 2013). Master regulators of vascular development and of blood and lymphatic vessel function, the VEGF family is involved in regulating angiogenesis, lymphangiogenesis and vascular permeability and in the stimulation of cell migration in macrophage lineage and endothelial cells (Shibuya, 2011; Koch and Claesson-Welsh, 2012). Significant downregulation of VEGF signaling was achieved by the use of chitosan nanoparticles in a nude mice xenografted model with human hepatocellular carcinoma (HCC) (BEL-7402) cells (Xu et al., 2009). In other studies, PEGylated nanoconjugated delivery systems (for inhibitors/siRNA) inhibited VEGF signaling by blocking receptor binding or expression thus inhibiting tumor angiogenesis (Schiffelers et al., 2004; Kim et al., 2006). VEGF signaling could be effectively targeted by the use of gold nanoparticles conjugated with anti-VEGF antibody in a study using primary CLL B cells resulting in the induction of apoptosis of these CLL B cells (Mukherjee et al., 2007).

\section{Nanomedical Targeting of the Notch Signaling Pathway}

Notch is a cell surface receptor. The interaction of a ligand with notch ensues cleaving of its intracellular domain which travels to the nucleus to regulate transcription. Notch signaling is an inherent part of cell fate assignation and pattern formation during development. The Notch signaling pathway is involved in regulating cell proliferation, cell fate, differentiation, and cell death (Ehebauer et al., 2006; Kopan, 2012). Efficacious targeting of Notch signaling was achieved in vitro and in vivo by the use of mesoporous silica nanoparticles carrying Notch inhibitor; $\gamma$-secretase inhibitor (Mamaeva et al., 2011, 2016). $\gamma$-secretase inhibitor conjugated with iron oxide nanoparticles was also effective for downregulating Notch signaling in hepatocarcinoma and glioblastoma stem cells (Orza, 2015). The use of poly(lactide-co-glycolide) (PLGA) nanoparticles to deliver $\gamma$-secretase inhibitor dibenzazepine was found to effectively target and downregulate Notch signaling in diet-induced obese mice (Jiang et al., 2017). Significant downregulation of Notch signaling and consequently arresting of tumor growth resulted from the administration of siDCAMKL-1 encapsulated poly(lactide-co-glycolide) nanoparticles in HCT116 xenografts (Sureban et al., 2011).

\section{Clinical Trials Involving Nanomedical Targeting of Signaling Pathways}

Paclitaxel is involved in the downregulation of JAK/STAT signaling pathway, inhibits PI3K/AKT signaling pathway and activates MAPK and TLR4 signaling (Wang et al., 2006; Fujita et al., 2018; Ren et al., 2018). A novel Cremophor EL-free polymeric micelle formulation of paclitaxel, Genexol-PM was subjected to a multicenter phase II study to evaluate its efficacy and safety in patients with histologically confirmed metastatic breast cancer (MBC). Forty-one women received Genexol-PM by intravenous infusion every 3 weeks without premedication until disease progression or intolerability. Thirty-seven patients who received Genexol-PM as a first-line therapy for their metastatic disease showed a response rate of $59.5 \%$ and two responses were reported in four patients treated in the second-line setting for their metastatic disease. Sensory peripheral neuropathy, myalgia, hypersensitivity reactions, neutropenia, and thrombocytopenia were the adverse effects reported (Lee et al., 2008). The tyrosine kinase EphA2 is involved in the suppression of the AKTmTORC1 and RAS-ERK pathways. A phase I clinical trial assessing the potency of a DOPC-based liposomal formulation targeting the tyrosine kinase EphA2 in patients with advanced and recurring solid tumors is underway (Bi-Wagner et al., 2017; Singh et al., 2018). A lipid-based nanoparticle formulation containing siRNAs targeting both vascular endothelial growth factor (VEGF) and kinesin spindle protein (KSP) (ALN-VSP) was tested on 41 patients with both hepatic and extrahepatic tumors. ALN-VSP was found to be generally well-tolerated (Tabernero et al., 2013). Protein kinase N3 (PKN3) has been identified as a downstream effector of the PI3K signaling pathway (Hattori et al., 2017). In a dose-escalation phase I clinical trial, the efficacy of a liposomal RNA interference therapeutic called Atu027 that targets the protein kinase N3 was evaluated. The results were promising, with disease stabilization for $41 \%$ of patients reported (Schultheis et al., 2014). The PLK1 (Pololike kinase 1) is a potent activator of the MAPK/ERK signaling 
pathway. Intravenous delivery of lipid nanoparticles containing therapeutic siRNA targeting PLK1, TKM-080301 has been developed and is currently in phase $1 / 2$ clinical trial for the treatment of neuroendocrine and adrenocortical cancers (BkLam et al., 2015; Wu et al., 2016).

\section{COVID-19: DISEASE, IMMUNE RESPONSE, IMMUNOPATHOLOGY AND CLINICOBIOLOGICAL PHASES}

\section{Disease}

SARS-CoV-2 is a novel beta coronavirus and is a positive stranded RNA virus (Ouassou et al., 2020). It is transmitted through direct/indirect or close contact with infected people; through respiratory droplets expelled from the infected person, aerosol transmission combined with droplet transmission or through contaminated surfaces (that contain respiratory droplets) (World Health Organization, 2020e). The mean incubation period ranges from 2.1 to 11.1 days and the median incubation period is 3 days (Dhama et al., 2020; Velavan and Meyer, 2020). Though other organ systems are also involved, SARS-CoV-2 primarily affects the respiratory system, with the lungs being the primary site of infection. The virus infects alveolar epithelial cells in the lungs by exploiting receptormediated endocytosis, with ACE2 as the entry receptor. The initial COVID-19 symptoms observed are fever, dry cough, tachypnea, and shortness of breath. Other symptoms include headache, muscle aches, tiredness, chest pain or pressure, diarrhea, dyspnea, nasal congestion, loss of taste/smell, chills, and nausea. Clinical examinations revealed elevated levels of LDH, AST, ALT, urea, creatinine. Inflammatory markers ESR, PCT, CRP, and D-dimer levels are also high in COVID-19 patients. On the other hand serum albumin, hemoglobin count and eosinophil count are decreased. Leucopenia, lymphopenia, neutrophilia are some other common clinical presentations; few patients also exhibit thrombocytopenia. The levels of inflammatory/modulatory cytokines and chemokines like IL-1, IL-2, IL-4, IL-6, IL-7, IL-8, IL-10, IL-12, IL-13, IL-17, IFN $\gamma$, TNF $\alpha$, HGF, VEGF, M-CSF, G-CSF, GM-CSF, IP-10, MCP-1, MIP-1 $\alpha$, CCL2, CCL3, CCL5, CXCL8, CXCL9, CXCL10 are also elevated. Radiological findings include the presence of ground glass opacities, patchy consolidation in the lungs. Pleural effusion, cavitation, calcification, and lymphadenopathy may also be reported (Costela-Ruiz et al., 2020; Esakandari et al., 2020; He et al., 2020; Lotfi et al., 2020; Mortaz et al., 2020; Parasher, 2020; Shah et al., 2020; Wang et al., 2020b; Yuki et al., 2020).

\section{Immune Response}

Initial viral recognition is crucial for mounting an innate and/or adaptive antiviral response. The innate immune response is initiated following the recognition of SARS$\mathrm{CoV}-2$ by pathogen-associated molecular patterns (PAMPs). Viral RNA/dsRNA/uncapped mRNA are recognized both by endosomal RNA receptors TLR3, TLR7, TLR8, TLR9 and by cytosolic RNA sensor RIG1/MDA5. This initial recognition by TLRs drives the complex TLR signaling that leads to the expression of various genes culminating in the production of antiviral cytokines; type I IFNs, IL-1 $\beta$, and IL-6. Recognition by PAMPs also results in the activation of NF- $\kappa \mathrm{B}$, which is a hallmark of most viral infections. This activation catalyzes the NK- $\mathrm{B}$ signaling pathways that trigger the expression of IFN genes involved in innate immunity. Taken together, this comprises the first line of defense against SARS-CoV-2 infection at the entry site. TLR recognition also triggers the pathogen-activated protein kinases (MAPKs) pathway through the mediation of MyD88. The production of type I IFN causes the activation of the JAK/STAT signaling via IFNAR that brings about the phosphorylation of transcription factors STAT1 and STAT2 by JAK1 and TYK2 kinases. Nuclear translocation of the transcription factors ensues, followed by the initiation of transcription of IFN-stimulated genes (ISGs) under the control of IFN-stimulated response element (ISRE) containing promoters. This manner of mounting of the type I IFN response promotes the effective suppression of both viral replication and dissemination at an early stage. Normally, viral antigens are presented via antigen presenting cells (dendritic cells, macrophages) to $\mathrm{CD}^{+}$T-helper cells that further sensitize $\mathrm{CD}^{+}$cytotoxic $\mathrm{T}$ lymphocytes. These cytotoxic T lymphocytes can blunt viral replication by directly killing infected cells and secrete antiviral cytokines including IFN and TNF $\alpha$. Recruitment of NK cells that takes place is vital for resistance of viral replication to eradicate virus-infected cells. Production of cytokines facilitates the recruitment of monocytes and neutrophils to the site of infection and the activation of other pro-inflammatory cytokines and chemokines like IL-1, IL-6, IL-8, IL-21, TNF $\beta$, and MCP1. Humoral immune response is mediated by $\mathrm{CD} 4^{+}$T-helper cell mediated activation of B-cells that produce virus-specific antibodies. Initially, within the first week, SARS-CoV-2 activates T-cells; and virus-specific memory $\mathrm{CD}^{+}$cells and $\mathrm{CD} 8^{+} \mathrm{T}$ cells peak within 2 weeks. However, in patients with severe COVID-19, a marked decrease in $\mathrm{CD}^{+}$cytotoxic $\mathrm{T}$ lymphocytes and $\mathrm{CD} 4^{+} \mathrm{T}$-cells is observed. Additionally, the surviving T-cells exhibit functional exhaustion. There is also a reduction in the NK cell count along with decreased functionality that promotes reduced clearance of infected and activated cells in addition to an unchecked elevation of tissue-damaging inflammation markers. In response to SARS-CoV-2, specific IgA, IgM ( $\sim 4-6$ days post exposure) and IgG ( $\sim 7-10$ days post exposure) are produced. The complement system is also involved in facilitating antiviral response. In severe COVID-19 patients, widespread complement activation is observed (Santoro et al., 2003; Thompson and Iwasaki, 2008; Schmitz et al., 2014; Astuti and Ysrafil, 2020; Azkur et al., 2020; Diao et al., 2020; Guihot et al., 2020; Iqbal, 2020; Prompetchara et al., 2020; Risitano et al., 2020; Sousa and Brites, 2020; Stephens and McElrath, 2020; van Eeden et al., 2020; Zheng M. et al., 2020).

Normally, airway mucus which lines the epithelial surfaces in the respiratory tract is involved in important innate immune function; it provides for a mode to effectively detoxifying noxious molecules mediated by the trapping and removal of pathogens from the airway via mucociliary clearance. Mucin glycoproteins are the major macromolecular constituents of mucus, in addition 
to proteoglycans, lipids, proteins and DNA which are also present in smaller quantities. Secreted mucins and membraneassociated mucins are the two major families of mucins. Among the two, membrane-associated mucins function as cell surface receptors for pathogens and also activate intracellular signaling pathways. The expression of secretary mucins is regulated by pleiotropic cytokines (IL-4, IL-13, IL-9) and proinflammatory cytokines (IL-1 $\beta$, IL-6, TNF $\alpha$ ). Transmembrane mucins on the other hand are selectively regulated by inflammation and inflammatory cytokines (IL-6, IFN $\gamma$, TNF $\alpha$, TGF $\beta$ ) and are also involved in the regulation of inflammatory responses themselves. JAK/STAT, TLR, NF- $\mathrm{B}$, Akt, MAPK/ERK signaling pathways are selectively modulated by transmembrane mucins. Infection with SARS-CoV-2 causes an allergic reaction in the mucosa of the respiratory tract that activates the secretion of mucin and modulates its chemical structure, facilitating the viral entry into the cells. Consequently, SARS-CoV-2 initiates mucus-mediated inflammatory pathways (Voynow and Rubin, 2009; van Putten and Strijbis, 2017; Earhart et al., 2020; Khan et al., 2021).

\section{Immunopathology}

In addition to activating antiviral immune responses, SARS-CoV2 is responsible for disrupting the normal protective immune response thus leading to an impaired immune system which promotes a dysfunctional immune response. The uncontrolled inflammatory and immune responses ensuing can lead to immunopathogenesis which can prove to be fatal in the severe and critical COVID-19 patients. Some of the manifestations and features of the immunopathogenesis observed in COVID19 patients are as follows. A highly impaired type I and III IFN response, which is characterized by absence of IFN $\beta$ and a low IFN $\alpha$ production and activity and is associated with persistent viral load in the blood and an exacerbated inflammatory response. Patients exhibit a significant decrease in $\mathrm{CD}^{+}{ }^{+} \mathrm{T}, \mathrm{CD}^{+}{ }^{+} \mathrm{T}, \mathrm{NK}$, and B cell number. Moreover, T-cells show exhaustion phenotypes and reduced functional diversity. Programmed cell death protein-1, $\mathrm{T}$ cell immunoglobulin domain and mucin domain-3 levels on $\mathrm{CD}^{+} \mathrm{T}$ cells are increased; killer cell lectin-like receptor subfamily $\mathrm{C}$ member 1 receptor expression on cytotoxic lymphocytes, including NK and $\mathrm{CD}^{+} \mathrm{T}$ cells, is also increased. Abnormal number of granulocytes and monocytes is found; increased neutrophils and an abnormal neutrophil-to-lymphocyte ratio is an indicator of severe disease in patients. Elevated levels of cytokines are observed; IL-1 $\beta$, IL- 6 , and IL-10 in particular. Increased antibodies and relatively high $B$ cell levels correlate with poor prognosis. Thrombotic complications including platelet activation, stasis of blood flow, microvascular pulmonary thrombosis, extensive diffuse alveolar damage and thrombi present within small peripheral vessels in the lungs are characteristic of the coagulopathy observed in patients (Hadjadj et al., 2020; Jacques and Apedaile, 2020; The Lancet Haematology, 2020; Yang et al., 2020; Peter et al., 2021).

COVID-19 pneumonia is also associated with mucus hypersecretion and mucus plugging. Autopsy reports on COVID-19 patients who succumbed due to hypoxia and ARDS have also confirmed the same; specifically reporting the following. Copious amounts of gray-white viscous fluid in the lungs and along the distal respiratory tract of COVID-19 patients has been reported. Large quantity of viscous secretions was seeping from the air sacs, white foamy mucus adhering in the airway, gelatinous mucus adhering in the bronchial lumen and muciod material within the bronchial branches have been reported. A very prominent feature of COVID-19 also observed was that the large amounts of highly viscous mucus caused obstruction to small airway, leading to infections, ventilator dysfunction, ARDS, and an uncorrectable hypoxia. Studies have established the expression of mucins in the epithelial cells of the lungs and also the accumulation of the same in the bronchoalveolar lavage fluid (BALF) of COVID-19 patients. Mucus accumulation and the aggregation of mucins with platelets can cause plugging of the pulmonary airways that adversely affects the blood-gas barrier resulting in induction of hypoxia and a diminished lung capacity. As airway mucus looses its antimicrobial activity within $24 \mathrm{~h}$ and can colonize bacteria thereafter, pulmonary infections can occur. Lung autopsies have of COVID-19 patients have also revealed superimposed bacterial pneumonia with suppurative bronchopneumonic infiltrates and bacterial abscesses. All this makes hypersecretion of airway mucus and mucus plugging one of the major causes of death in critically ill COVID-19 patients. A study on critically-ill COVID-19 patients assessed the levels of mucin proteins MUC1 (membrane-tethered) and MUC5AC (secreted) in the airway mucus and reported higher levels of both MUC1 and MUC5AC than healthy controls (Bikdeli et al., 2020; Carsana et al., 2020; Deshpande, 2020; Farooqi et al., 2020; Lax et al., 2020; Liu et al., 2020; Menter et al., 2020; Wang et al., 2020a; Zhang Y. et al., 2020; Lu et al., 2021).

Although COVID-19 primarily affects the respiratory system, increasing evidence has shown that it is essentially a multisystemic disease. Other organs and systems can be affected from the beginning of infection or subsequently after respiratory infection. Studies have revealed that SARS-CoV-2 positive cells were most frequently present not only in the lungs, but also in the heart, kidneys, gastrointestinal tract, submandibular glands and liver during the early stages of the disease. In case patients with longer disease courses, the presence of SAR-CoV-2 positive cells was sporadic in these organs. SARS-CoV-2 induces diffuse alveolar damage in the lungs that causes pneumonia, hypoxia, ARDS, and critical disease. Some of the other organ systems affected are briefly discussed as follows. Cardiovascular complications, including myocardial injury, heart failure, and arrhythmias have been reported. Over a third of COVID-19 patients were found to develop a broad spectrum of neurological symptoms which affected the central nervous system, peripheral nervous system, and skeletal muscles, including anosmia and ageusia. Hematological complications are frequent as also are gastrointestinal effects, symptoms of the same are also frequently encountered and may persist for several days. Other systems like the kidneys, the liver, the endocrine organs, the skin and the eyes are also affected by the systemic COVID-19 disease. Whilst SARS-CoV-2 does directly effect the different body organs and systems, the systemic disease is a consequence of the pathobiological immune alterations; the overwhelming 
inflammatory response in particular. Inflammatory changes in the heart with lymphohistiocytic infiltration, myocyte injury, and fibrosis post-COVID-19 have been reported. In the brain, the presence of lymphocytic infiltrate, massive activation of microglia with formation of nodules, presence of $\mathrm{T}$ cells could be identified in COVID-19 patients. The olfactory bulbs presented the most pronounced inflammatory reaction and excessive inflammation of the medulla oblongata was observed. In the liver, mild hepatic portal inflammation was present. Tubular epithelial cell vacuolization was frequently seen in the kidneys, as reported by a study on COVID-19 patients. In the bone marrow, discrete fibrosis, and abnormalities in megakaryocytes; increased numbers and abnormal morphology was noted (Gavriatopoulou et al., 2020; Massabeti et al., 2020; Munjal et al., 2020; Rabaan et al., 2020; Schurink et al., 2020; Temgoua et al., 2020).

\section{Clinicobiological Phases of COVID-19}

Researchers, having extensively studied the course of COVID-19 have identified that there are three critical clinicobiological phases of the disease. The clinicobiological phases of COVID-19 have been identified as the initial asymptomatic/presymptomatic disease phase, the propagating phase with mild/moderate/severe symptoms and the complicating phase of COVID-19 disease with impaired/disproportionate and/or defective immunity. Approximately $50-80 \%$ of individuals infected with SARS-CoV-2 are asymptomatic. After an incubation period of $\sim 5.2$ days, onset of symptoms occurs. In the pre-symptomatic phase of COVID-19 disease, two organ systems are involved; the respiratory and the gastrointestinal systems. Infection initially involves the upper respiratory system and then proceeds to the lower respiratory system. Mild fever, cough (dry), sore throat, oropharyngeal mucositis, nasal congestion, malaise, headache, muscle pain are the symptoms that suggest the occurrence of upper respiratory tract infection. Smell and taste disorders (anosmia and dysgeusia) and nausea and diarrhea are the characteristics of the gastrointestinal symptoms of the initial clinicobiological phase of COVID-19 disease. In the second phase of COVID-19 disease, the infection proceeds to the lower respiratory system, myocardium and other organ systems. Moderate to severe pneumonia, severe dyspnea, respiratory distress, tachypnea ( $>30$ breaths/min), and hypoxia $\left(\mathrm{SpO}_{2}<90 \%\right.$ on room air) mark this phase of COVID-19 disease. Systemic disease involving other organ systems occurs in the propagating phase, which is the second clinicobiological phase of COVID-19. The effects of disease can be observed on several organ systems, like the cardiovascular system (direct myocardial injury from hemodynamic derangement or hypoxemia, inflammatory myocarditis, stress cardiomyopathy, microvascular dysfunction or thrombosis due to hypercoagulability, or systemic inflammation), the hematopoietic system (lymphopenia, elevated factor VII, elevated fibrinogen, circulating prothrombotic microparticles, neutrophil extracellular traps), the renal system [acute kidney injury (AKI), hematuria, or proteinuria, acute tubular injury], the central nervous system (hyposmia or anosmia), and others systems also (conjunctivitis, Guillain-Barré syndrome). In the third clinicobiological phase of COVID19 disease, the clinical status of the patient worsens; as the disease has spread all over the body, including majority of the organ systems; respiratory system, cardiovascular system, gastrointestinal system, bone marrow and hematopoietic system, renal system, liver, and other systems. In this complicating phase of COVID-19 disease, patients develop ARDS, sepsis, MOF and septic shock and the fatality rate in this patient group is high. Severe lymphopenia, elevated leukocyte and neutrophil counts, extremely high D-dimer levels, increasing levels of blood urea and creatinine, severe hypoxia, elevated levels of proinflammatory cytokines, hyperbilirubinemia, acidosis, high lactate, coagulopathy, and thrombocytopenia are the features of the terminal phase of COVID-19 syndrome that is associated with poor clinical outcome (Turk et al., 2020a,b).

\section{SIGNALING CASCADES IN COVID-19 COVID-19 and the JAK/STAT Signaling Pathway}

A state of hypercytokinemia is observed in COVID-19 patients with severe disease and this correlates with adverse clinical outcome. The JAK/STAT signaling pathway is activated by several cytokines and is a major signaling mediator for cytokines and chemokines. SARS-CoV-2-mediated hyperinflammation is primarily brought about via the JAK/STAT signaling cascade that can be triggered both by the SARS-CoV-2 structural and non-structural proteins that eventually results in elevated cytokine levels. The escalating cytokine levels (IL-6, IL-1 $\beta$, and IFN $\gamma$ ) further stimulate the activation of the JAK/STAT signaling pathway in patients, which results in a degenerative feedback loop being established (Battagello et al., 2020; Luo W. et al., 2020; Satarker et al., 2020). SARS-CoV-2 inhibits STAT1 phosphorylation which results in blocking ISGs transcription in monocyte-derived dendritic cells and macrophages, thus contributing to the impairment of interferon responses. An impaired STAT1 function effectuates a compensatory signaling shift via STAT1-independent pathways and a STAT3dependent transcriptional profile becomes dominant. This results in a positive feedback loop being established between STAT3 and plasminogen activator inhibitor-1 (PAI-1). Such a transcriptional rewiring toward STAT3 and upregulation of PAI1 drives the rapid coagulopathy/thrombosis, proinflammatory conditions, profibrotic status, and T cell lymphopenia observed in COVID-19 (Matsuyama et al., 2020).

The JAK/STAT signaling cascade is also involved in the regulation of the production of mucin proteins. Activation of STAT6 mediated by IL-4 via its receptor results in the activation of the MUC5AC gene complex consisting of MUC1/2/4. The elevated levels cytokines including IL-4 that can subsequently drive JAK/STAT signaling could be responsible for the higher levels of MUC5AC and MUC1 that were observed in the airway of COVID-19 patients (Xia et al., 2017; Khan et al., 2021).

\section{COVID-19 and the TLR Signaling Pathway}

TLR signaling is vital in the initial stages of an infection as it is responsible for the initiation of innate immune response. In patients with severe COVID-19, the levels of pro-inflammatory cytokines are significantly high; many of which are products 
of TLR signaling. While the spike protein of SARS-CoV-2 interacts with TLR1, TLR4, and TLR6, highest binding energy is reported with TLR4. TLR4 signaling in particular, has been implicated in the initiation and progression of inflammatory disease. Majority of the immunopathological consequences in severe COVID-19 disease is a consequence of the interaction of the SARS-CoV-2 antigens with the TLRs. Furthermore, studies have demonstrated that TLR cascades are a vital mediator of COVID-19 immunopathogenesis. In a study of the immune transcriptome of 28 COVID-19 patients (8 severe/critical and $20 \mathrm{mild} /$ moderate cases), the expression of TLR4 and its downstream signaling molecules were found to be upregulated indicating that upregulated TLR signaling could be a significant contributor to the uncontrolled pathological inflammation (Brandão et al., 2020; Onofrio et al., 2020; Sohn et al., 2020; Patra et al., 2021).

\section{COVID-19 and the NF-кB Signaling Pathway}

The interaction of viral material with TLR also triggers the $N F-\kappa B$ signaling cascade. NF- $\kappa$ B signaling plays a significant role in the enhancement of gene expression of cytokines and chemokines which are further involved in inflammatory signaling. SARS-CoV-2-induced NF- $\mathrm{B}$ activation induces the production of IL-1, IL-2, IL-6, IL-12, TNF $\alpha$, LT- $\alpha$, LT- $\beta$, GMCSF, and other chemokines in cells like the macrophages of lung, liver, kidney, central nervous system, gastrointestinal system, and cardiovascular system. In severe COVID-19, hyper-activation of the NF- $\mathrm{B}$ pathway has been reported. This hyper-activation of NF- $\kappa$ B is mediated by a hyper-activated IL- 6 amplifier response and STAT3 that eventually results in multi-inflammatory responses (Battagello et al., 2020; Hariharan et al., 2020).

The production of cytokines IL-1B, IL- 6 , IL- 8 , and TNF $\alpha$ which are modulated by NF-кB signaling are known to cause pulmonary inflammation and also promote mucus hypersecretion, indicating that NF- $\kappa \mathrm{B}$ signaling can also mediate mucus hypersecretion in COVID-19 (Wang et al., 2007; Hariharan et al., 2020).

\section{COVID-19 and the PI3K/AkT Signaling Pathway}

The involvement of the PI3K/AkT pathway in lung injury and lung fibrogenesis has been established. This pathway has also been implicated in several inflammatory diseases. In COVID19 disease, the PI3K/AkT signaling pathway is up-regulated. In a study carried out on Huh7 cells infected with SARS$\mathrm{CoV}-2$, marked alterations of PI3K/AkT signaling was observed (Appelberg et al., 2020; Hou et al., 2020; Somanath, 2020; Xia et al., 2020).

\section{COVID-19 and the mTOR Signaling Pathway}

Antibody-dependent enhancement (ADE), particularly suboptimal antibody-elated responds and the cross-reactive antibodies associated with ADE could be a significant promoter of hypercytokinemia in COVID-19. Cross-reactive antibodies can promote the entry of virus into monocytes/macrophages via the $\mathrm{Fc}$ receptor which eventually results in viral replication and release after immune escape. Autopsies reports of COVID19 revealed that mainly monocytes/macrophages were the exuding cells in the alveolar cavity of patients. Virus inclusions were detected in the macrophages of these patients. The mTOR signaling pathway has an important role to play in the development of antibody producing B-cells. An inhibition of mTOR curbs the proliferation of memory B cells that will result in a restrained early cross-reactive antibody production, lower the $\mathrm{ADE}$ and consequently control the cytokine storm in severe cases of COVID-19. mTOR activation (in a STAT3 dependent or independent manner) can be mediated by IL-6, which is elevated in COVID-19 patients. Thus, mTOR inhibition can also dampen the cytokine storm by targeting the mTOR-NLRP3-IL-1 $\beta$ axis of the IL- 6 pathway. At the same time, SARS-CoV-2 is a positive sense single-stranded RNA virus and can potentially exploit the mTOR signaling cascade and use the host translational machinery for viral replication. For this purpose also, the use of mTOR inhibitors in COVID-19 treatment will be useful; to limit the multiplication of virus and infection. An in vitro study on SARS-CoV-2-infected Huh7 cells revealed significant modulations of the mTOR pathway during the course of the SARS-CoV-2 infection (Appelberg et al., 2020; Ramaiah, 2020; Yarmohammadi et al., 2020; Zheng Y. et al., 2020).

\section{COVID-19 and the MAPK/ERK Signaling Pathway}

Coronaviruses have been implicated in exploiting the host MAPK/ERK signaling cascade for viral pathogenesis. The probability that the same holds true for SARS-CoV2 is high. Furthermore, the p38 MAPK pathway which is a proinflammatory pathway is involved in facilitating the production of pro-inflammatory cytokines including TNF $\alpha$, IL-1 $\beta$, and IL-6. TNF $\alpha$ and IL-1 $\beta$ are in turn involved in the activation of NF- $\kappa \mathrm{B}$ signaling, altogether mediating hypercytokinemia, inflammation, thrombosis, and vasoconstriction in COVID-19. Modulation of MAPK signaling can also be arbitrated by IL-6, non-canonically. MAPK signaling cascades have also been incriminated lung and heart injury. In the study carried out in SARS-CoV-2 infected Huh7 cells, the MAPK signaling pathways were found to be upregulated (Appelberg et al., 2020; Battagello et al., 2020; GhasemnejadBerenji and Pashapour, 2020; Grimes and Grimes, 2020; Hou et al., 2020; Wehbe et al., 2020).

The MAPK signaling pathway is also involved in the regulation of the secretion of mucus. Mucus hypersecretion in COVID-19 disease can be mediated by MAPK/ERK via the action of IL- 6 and TNF $\alpha$. The binding of IL- 6 to its receptor IL6R activates Growth factor receptor-bound protein 2 and Son of Sevenless complex (GRB2/SOS), further activating Ras and Raf signaling cascades, which in turn activate JNK via the p38/MAPK pathway. The activation of JNK results in the upregulation of MUC5AC gene in the airway epithelium which enhances the mucus hypersecretion. TNF $\alpha$ increases the expression of EGFR in the airways, that can activate Ras, Raf, and MUC2 via 
Erk1/2 which can also result in the hypersecretion of mucus (Khan et al., 2021).

\section{COVID-19 and the AMPK Signaling Pathway}

The effect of SARS-CoV-2 on AMPK signaling was studied in human bronchial epithelial cells NCI-H1299 and monkey kidney cells (VeroFM) infected with the Munich strain [multiplicity of infection (MOI) of 0.0005] or heat-inactivated (mock-infected cells) SARS-CoV-2 virus. SARS-CoV-2 was found to reprogram the metabolism in the infected cells, limit the activation of AMPK thus downregulating AMPK signaling significantly. Activation of AMPK can effectively switch off mTOR signaling and also inhibit NF- $\mathrm{B}$ pathway. Thus, AMPK signaling brings about a shift from proinflammatory responses toward anti-inflammatory and repairing response. Additionally, AMPK signaling activates Nrf2 and AMPK-Nrf2 pathway and ameliorates pneumonia. Taken together, this implies that AMPK activation can block hyperinflammation and lung injury in COVID-19 (Ayres, 2020; Azar et al., 2020; Chen et al., 2020; Icard et al., 2020; Maiese, 2020; Nils et al., 2020; Xu et al., 2020).

\section{COVID-19 and the TGF Beta Signaling Pathway}

TGF- $\beta$ is a potent fibrogenic cytokine. As a cytokine, it promotes the recruitment neutrophils, macrophages and lymphocytes into the lungs during SARS-CoV-2 infection. This brings about an increase in the total TGF- $\beta$ locally. The amount of active TGF- $\beta$ gradually builds up in the lungs during the course of infection. TGF- $\beta$ signaling promotes the establishment of fibrosis and induces a loss of fluid homeostasis in the lungs which ultimately results in functional failure of the lungs and death of the patients in severe COVID-19 disease. Upregulation of the TGF beta signaling cascade results a consequence of SARS$\mathrm{CoV}-2$ infection. Additionally, TGF- $\beta$ signaling drives activated $\mathrm{B}$ cells to switch to the terminal antibody class IgA2, which have a minimal contribution toward humoral immunity against SARS-CoV-2 (Chen, 2020; Delpino and Quarleri, 2020; Evans and Lippman, 2020; Ferreira-Gomes et al., 2020; Reiken et al., 2021).

\section{COVID-19 and the VEGF Signaling Pathway}

Increased expression of VEGF correlates with disease severity of COVID-19. The plasma levels of VEGF in COVID-19 patients are also increased. The genes encoding VEGF-A and VEGF-C are also upregulated in patients. VEGFs are important factors in acute lung injury and ARDS; the role played by VEGF and VEGF signaling in the pulmonary endothelial dysfunction observed in COVID-19 is indisputable. VEGF signaling mediated by VEGF released from platelets is involved in activating the coagulation cascade that is characterized by increased fibrin generation, thrombosis in larger vessels, blood clot deposition in the microvasculature and promoting the coagulopathy observed in COVID-19. Hypoxia also induces the expression of VEGF causing plasma extravasation and pulmonary edema, further increasing tissue hypoxia. VEGF signaling also promotes inflammation in the lung. In a study on rhesus macaques infected with SARS-CoV-2, the old macaques exhibited downregulation of genes associated with VEGF signaling unlike the juvenile macaques; which is remarkable, considering that elderly COVID19 patients have increased levels of VEGF. In another study in rodents infected with SARS-CoV-2, it was found that the spike protein subverts VEGF-A/NRP-1 pro-nociceptive signaling causing amelioration of VEGF-A mediated pain (Chernyak et al., 2020; Colantuoni et al., 2020; Jin et al., 2020; Meini et al., 2020; Moutal et al., 2020; Perico et al., 2020; Rosa et al., 2020; Teuwen et al., 2020; Turkia, 2020; Pang et al., 2021).

\section{COVID-19 and the Notch Signaling Pathway}

Abnormal Notch signaling contributes considerably to pathogenesis in different lung diseases. The Notch signaling pathway is a positive regulator of IL-6 production in macrophages. In turn, IL-6 amplifies Notch signaling, that can create a positive feedback loop for IL-6 production. TLR activation can also induce Notch signaling indirectly, through STAT3. This gives way to the existence of a positive feedback loop between Notch signaling and JAK/STAT3 pathway, driving Notch-boosted IL-6. With respect to Th cells, Notch signaling varies; Notch signaling through Dll1,4 ligands promotes inflammatory Th1/Th17 cytokine production while Jagged1 blunts the IL-6-induced Th17 activation. It is also speculated that Notch signaling can effectively prevent SARS-CoV-2 infection by reducing the levels of furin that would interfere with viral entry into the cell. In the study with rhesus macaques infected with SARS-CoV-2, juvenile macaques exhibited upregulated Notch signaling pathways. NOTCH1 was found to be downregulated in SARS-CoV-2 infection (Hildebrand et al., 2018; Islam and Khan, 2020; Rizzo et al., 2020).

A diagrammatic representation of SARS-CoV-2 infection and subsequent host immune response with emphasis on signaling cascades is found in Figure 1.

\section{CURRENT TREATMENT METHODS TARGETING PIVOTAL SIGNALING PATHWAYS IN COVID-19}

Several studies have been undertaken and clinical trials are underway to evaluate the efficacy of different small molecule inhibitors that can target some of the aberrant signaling pathways in COVID-19. Ruxolitinib, baricitinib; an inhibitor of JAK1 and JAK2 and tofacitinib; an inhibitor of JAK1, JAK2, JAK3, and TYK2 being are being used in case of severe COVID19 and/or are under ongoing phase I/II/III/IV clinical trials for COVID-19 treatment (Luo W. et al., 2020). Validation of a few molecules like imiquimod, M5049, hydroxychloroquine sulfate, chloroquine phosphate, EC-18, PUL-042 that block TLR signaling and/or act as agonists of intracellular TLRs is being performed in phase I/II/III clinical trials (Patra et al., 2021). Clinical trials involving two glucocorticoids, methylprednisolone and dexamethasone which potentially inhibit the NF-кB pathway and control the hyperinflammatory state in COVID-19 are ongoing; these corticosteroids are also being used in case of 


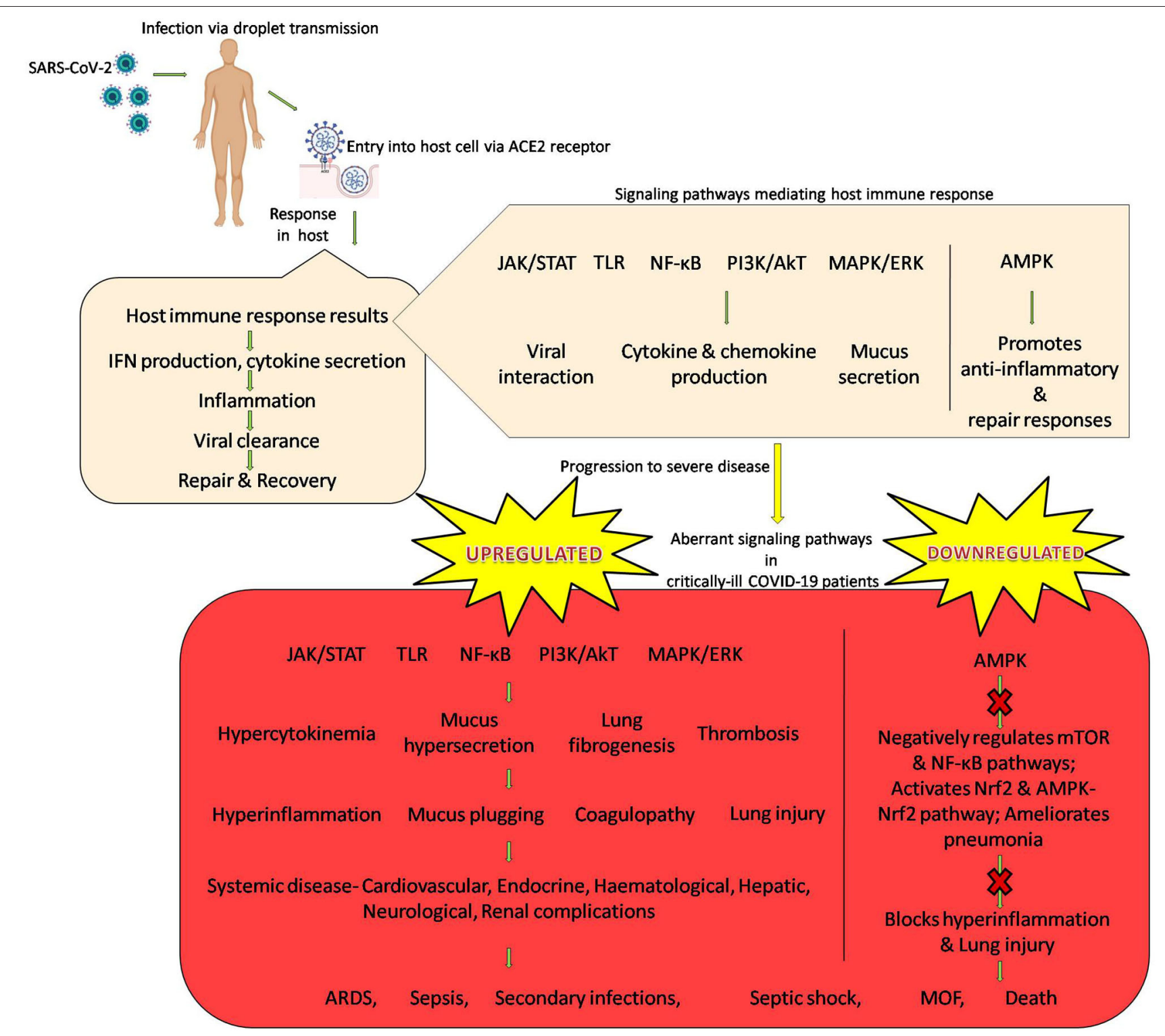

FIGURE 1 | SARS-CoV-2 infection and host immune response with emphasis on signaling cascades.

severe COVID-19 (Hariharan et al., 2020). The efficacy of sirolimus, an mTOR inhibitor for the treatment of patients with COVID-19 is being evaluated in two small-scale clinical trials (Zheng Y. et al., 2020). A clinical trial involving bevacizumab, a humanized monoclonal antibody that targets VEGF is also underway (Yarmohammadi et al., 2020).

Though the various inhibitors of these signaling cascades can efficiently target the respective signaling cascade, their use is often associated with adverse effects. GI toxicity, risk of opportunistic infections, immunosuppression, headache, dizziness are some side-effects of the use of ruxolitinib. Upper-respiratory tract infections, thromboembolic events, nasopharyngitis, headache are some of the adverse effects reported with the use of baricitinib. GI perforations, blood clots, angioderma, hepatotoxicity, lymphopenia, hepatitis, pulmonary embolism are some of the negative effects observed with the use of tofacitinib (Luo W. et al., 2020). Fever, headache, myalgia, arthralgia, pain can result from the treatment with imiquimod (Angelopoulou et al., 2020). GI effects, cardiomyopathy and neurological adverse effects can occur on treatment with chloroquine and hydroxychloroquine treatment (Gevers et al., 2020; U.S. Food and Drug Administration, 2020). Methylprednisolone and dexamethasone treatment can also cause side-effects (Alessi et al., 2020; Edalatifard et al., 2020). The use of mTOR inhibitors for treatment can also result in potential side effects (Husain and Byrareddy, 2020).

Among the many advantages of nanotechnology treatment strategies, one of the most important advantage is that the 


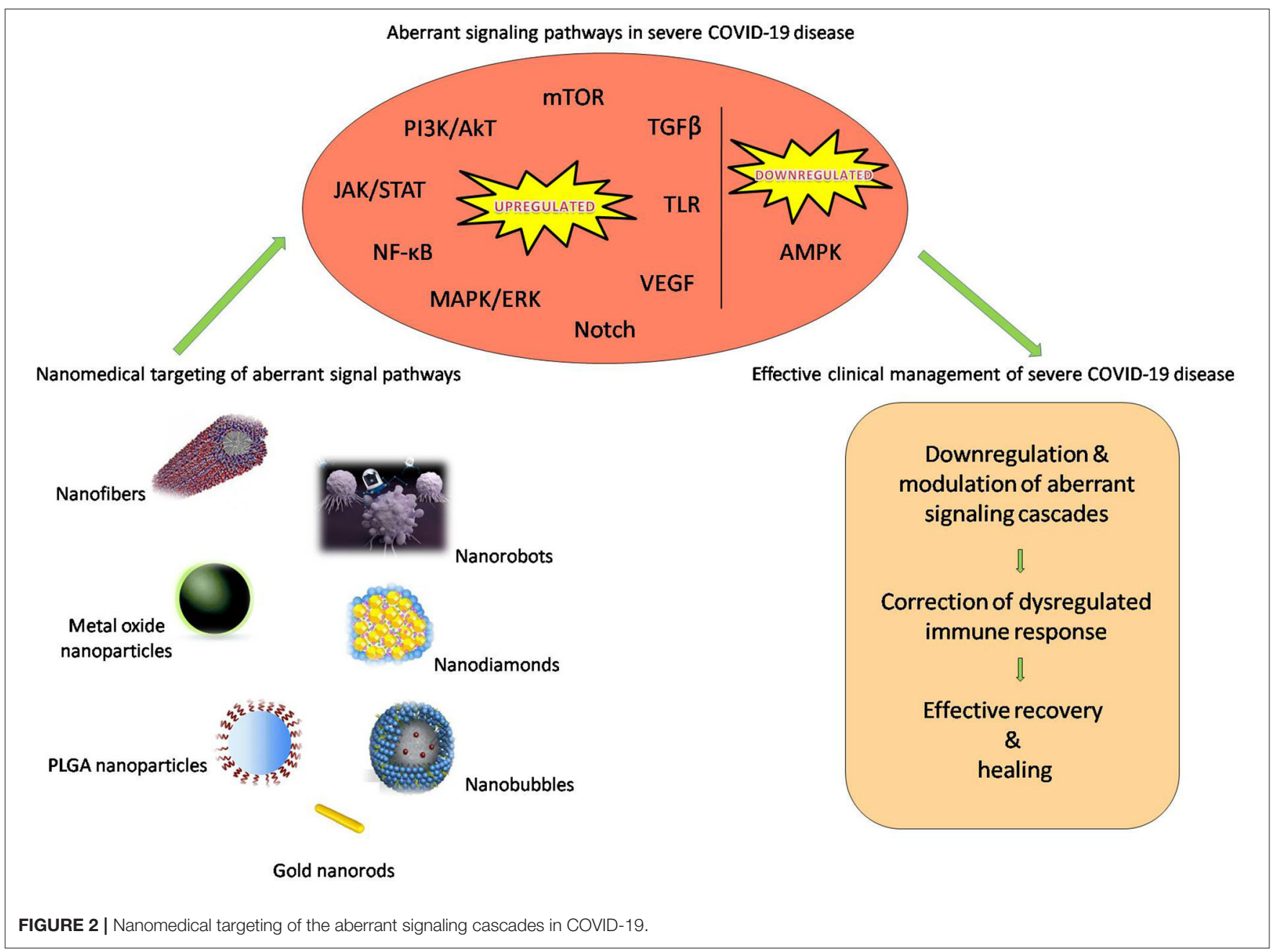

side effects of the drug can be greatly reduced (De Jong and Borm, 2008; Sutradhra and Amin, 2014). This warrants that the use of nanomedical approaches to target these signaling cascades is a promising strategy to curb the rampant state of hyperinflammation and effectively treat COVID-19.

\section{NANOMEDICAL TARGETING OF PIVOTAL SIGNALING PATHWAYS IN COVID-19}

Identifying important signaling pathways that are altered; either upregulated or downregulated during SARS-CoV-2 infection will throw light on the most relevant molecular cascades implicated in the biological processes and unveil the key molecular players that may be targeted to reduce the immune dysfunction and consequently severe COVID-19 disease. A very interesting observation made by a group of researchers is that during their analysis of the literature on COVID-19 and related topics, they noticed many similarities in the pathogenesis of COVID-19 and cancers. Signaling cascades like JAK/STAT, NF-кB, mTOR, MAPK/ERK, VEGF that are dysregulated in COVID-19 are also implicated in cancer development and progression. Nanomedical targeting of these pathways have been the subjects of extensive clinical investigations and clinical trials with respect to cancer treatment. As the ground work is already accomplished; i.e., the efficacy of nanomedical approaches to target signaling cascades is established, extending those findings to COVID-19 treatment is not a far cry.

Nanotechnology has much to offer in the fight against the COVID-19 pandemic. The use of nanotechnology to deliver immunomodulatory drugs in COVID-19 will be advantageous; drug delivery to physiologically in-accessible sites is facilitated, specificity and targeting is improved, reduced drug distribution to non-target tissues minimizes possible side effects, the large surface-to-volume ratio of NP increases drug loading and the inherent virucidal activity of NP (gold/silver) is a bonus point (Bhavana et al., 2020; Palestino et al., 2020; Weiss et al., 2020). Some strategic guidelines for the development of nanotherapeutics to treat COVID-19 include an appropriate nanocarrier selection that will bypass the conventional limitations of the drug candidate, chemical altering/(re)engineering the drug molecule for improved compatibility with the nanocarrier and employing nanocarriers for multiple drug molecules (Chauhan et al., 2020). 
Though the fact that nanomedical drug-delivery systems improves existing therapeutics is established, the practical application in viral diseases is vastly underexplored and greatly underused; as observed in the SARS-CoV-2 pandemic (Mainardes and Diedrich, 2020; Tyagi et al., 2021). Nanotechnology has been introduced into antiviral research before, but its prospects for success with SARS-CoV-2 are better than one might imagine, given that SARS-CoV-2 and nanomaterials are similar in size, SARS-CoV-2 $(60-140 \mathrm{~nm})$ is also near in size to most current FDA-approved nanomaterials, nanomaterials can co-deliver multiple drugs and allow drug targeting and control release (Tang et al., 2021). Nanomedical approaches for the treatment COVID-19 is being touted as an innovative and an effective treatment strategy (Jindal and Gopinath, 2020; Ruiz-Hitzky et al., 2020; Talebian and Conde, 2020). Nanoencapsulation of drugs may contribute to the development of safer treatments for COVID-19 (Mainardes and Diedrich, 2020). Currently, 16 nano-based vaccines are under $\mathrm{R} \& \mathrm{D}$ for the prevention of COVID-19 by leading institutes including NIH and Moderna, Novavax Inc., Pfizer, University of Tokyo, St. Petersburg Scientific Research Institute of Vaccines and Serums and CanSino Biologicals. Inc. (Campos et al., 2020; Nanomedicine the COVID-19 vaccines, 2020). A few studies to evaluate the efficacy and feasibility of the use of nano-delivery systems for COVID-19 treatment are also being explored. Novochizol aerosols are chitosan nanoparticles that have been developed by researchers in Cyprus that allow the encapsulation of multiple drugs to be efficiently delivered to the epithelial tissue of the lungs with controlled release to treat severe COVID-19. Iron oxide nanoparticles that have already been approved for the treatment of anemias have been found to interact with the S1-RBD of SARS-CoV-2 in molecular docking studies thus presenting a dual advantage for COVID-19 treatment. The use of theranostic nanoparticles for intranasal administration for COVID-19 therapy is also being explored. The FDA-approved gold-containing triethyl phosphine, commonly called auranofin was reported to inhibit the replication of SARS-COV-2 in vitro in human cells at low micro molar concentration. Auranofin treatment was also found to bring about a significant reduction in the expression of SARSCOV-2-induced cytokines in human cells. Auranofin-loaded nanoparticles have also been prepared [poly(lactic-co-glycolic acid) (PLGA) NPs], indicating that they could be a useful drug to limit SARS-CoV-2 infection and associated lung injury due to its antiviral, anti-inflammatory, and anti-reactive oxygen species (ROS) properties (Díez-Martínez et al., 2016; Rothan et al., 2020; Ghaffari et al., 2021). Silver nanoclusters coating deposited on facial masks (directly applicated on a FFP3 mask) was found to posses virucidal effect and completely reduced the titer of SARS-CoV-2 to zero in a study undertaken (Balagna et al., 2020). Cell nanosponges prepared with plasma membranes derived from human macrophages or pulmonary type II epithelial cells that attract bind to and neutralize SARS-CoV-2 have also been developed (Cavalcanti and Nogueira, 2020; Zhang Q. et al., 2020).

With the expertise from earlier studies on nanomedical targeting of aberrant signaling pathways in cancer research, the current research on nano-delivery systems for COVID-19 can be extended to target upregulated/activated signaling pathways (JAK/STAT, TLR, NF-кB, PI3K/AkT, mTOR, MAPK/ERK, TGF beta, VEGF, Notch cascades) or the downregulated/inactivated pathways (AMPK cascades) for correcting the dysregulated immune response characteristic in severe COVID-19. The downregulation of STAT3, inhibition of TLRs (TLR2; TLR3; TLR4; TLR5), NF-кB, PI3K/AkT, mTOR, MAPK/ERK/p53, modulation of AMPK, suppression of TGF- $\beta$, VEGF, and Notch which has been successfully achieved in several studies can be tested for efficacy in COVID-19 also. The use of novel futuristic delivery systems such as nanorobots, nanobubbles, nanofibers, and nanodiamonds for this purpose is also very promising. Nanorobots, made up of inorganic or polymeric nanomaterials, modified with biomimetic materials are capable of delivering various materials with high accuracy. In addition to a payload compartment to load the drug, they posses a miniature camera to navigate through the bloodstream and find the direct pathway to the cell; consequently targeting the drug delivery directly to the site of action. This can aid in the precise targeting of aberrant signaling cascades in COVID-19. Nanobubbles have an oxygen-containing core and can be loaded with drugs and combined with ultrasound techniques to facilitate ultrasoundguided (minimally invasive) site-specific delivery. They can prove useful, not only for the delivery of various inhibitors for targeting upregulated signaling cascades but also for supplying oxygen to the hypoxic areas since they possess an oxygen-containing core. This dual advantage makes nanobubbles a lucrative nanodelivery system for addressing both the hyperinflammation and hypoxia in COVID-19. Nanofibers are another potential novel drug delivery systems that have already been explored for the delivery of antiviral (anti-HIV, influenza) drugs. With unique properties like large surface area and porosity with small pore size and high mechanical strength and capability to get surface modified, tunable release of drugs could be achieved in experimental studies. One of the most promising nanocarbon materials, nanodiamonds posses multiple advantages, safety, structural stability, biocompatibility, non-toxicity, increased loading, solubility, bioavailability, and stability of the drug along with prolonged circulation times. They have been used for the delivery of antiviral drugs, various anticancer drugs, siRNAs, hormones, vitamins, and proteins. The use of nanodiamonds for the delivery of inhibitors for specific upregulated signaling pathways in COVID-19 can mediate better availability, stability and action of the drug (inhibitor) with minimal or even no side effects. Future research exploring the functionalities, safety, and efficacy of these novel nanodelivery systems to target aberrant signaling pathways in COVID-19 in the following months will be critical to exploit the unique properties and advantages that these nanodelivery systems offer (Chakravarty and Vora, 2020). This novel treatment approach can indeed prove powerful for clinical management of the severe COVID-19 cases and can effectively prevent the transition from mild to severe stages. This treatment approach of nanomedical targeting signal pathways to dampen the hyperinflammation and prevent severe COVID19 can revolutionize the fight against COVID-19 and may provide solutions to address the ongoing pandemic. However, a 
thorough evaluation is crucial to avoid any detrimental effects of targeting signaling pathways, which could include impeding the protective host immune response or the interference with the viral clearance mechanism of the host. A word of caution, although nanostructures are attractive delivery systems for medicine, two decades of nanotoxicology research has shown that the interactions of nanomaterials with cells, animals, humans and the environment are extremely complex. They have been linked to cell apoptosis, inflammation, worsening of asthma, fibrosis, chronic inflammatory lung diseases, and carcinogenesis. Responsible research that takes into consideration all aspects including protocols, benefits, possible pitfalls, and dangers is an absolute prerequisite. Thorough investigation and clinical trials will aid in the development of a sustainable nanotechnological solution for COVID-19 employing safe nanomaterials that can be used effectively without any adverse effects (Contera et al., 2020; Jones et al., 2020; Rai et al., 2020).

The use of nanomedical targeting of the aberrant signaling cascades in COVID-19 is diagrammatically representated in Figure 2 .

\section{CONCLUSION}

With the fact that the ongoing pandemic caused by SARS-CoV-2 has been raging successfully for over a year, the search for newer, novel strategies to contain it is the need of the hour. Patients with severe COVID-19 exhibit immune dysregulation, which can be traced back to aberrant signaling pathways. This modulation (upregulation/inactivation) of signaling pathways like JAK/STAT, NF-кB, TLR, mTOR, AMPK, Notch pathways drive the state of hypercytokinemia, hyperinflammation and coagulopathy that increase the severity of disease, slower the process of recovery and can also result in mortality in COVID-19. Nanomedical targeting of these signaling pathways has already been studied for the treatment of inflammatory diseases and cancer, in the past decade. The use of some nano-delivery systems are in the clinical stages, while some are in the clinical trial stage. Harnessing the potential of nanoscale drug delivery systems like liposomes, gold nanoparticles, metal oxide nanoparticles, nanobubbles, nanofibers, nanodiamonds for COVID-19 therapy will certainly

\section{REFERENCES}

Alessi, J., de Oliveira, G. B., Schaan, B. D., and Telo, G. H. (2020). Dexamethasone in the era of COVID-19: friend or foe? An essay on the effects of dexamethasone and the potential risks of its inadvertent use in patients with diabetes. Diabetol. Metab. Syndr. 12:80. doi: 10.1186/s13098-020-00583-7

Angelopoulou, A., Alexandris, N., Konstantinou, E., Mesiakaris, K., Zanidis, C., Farsalinos, K., et al. (2020). Imiquimod - a toll like receptor 7 agonist - is an ideal option for management of COVID 19. Environ. Res. 188:109858. doi: 10.1016/j.envres.2020.109858

Appelberg, S., Gupta, S., Akusjärvi, S. S., Ambikan, A. T., Mikaeloff, F., Saccon, E., et al. (2020). Dysregulation in Akt/mTOR/HIF-1 signaling identified by proteo-transcriptomics of SARS-CoV-2 infected cells. Emerg. Microbes Infect. 9, 1748-1760. doi: 10.1080/22221751.2020.1799723

Arms, L., Smith, D. W., Flynn, J., Palmer, W., Martin, A., Woldu, A., et al. (2018). Advantages and limitations of current techniques for prove to be advantageous. The targeting of errant signaling pathways that are responsible for driving hyperinflammation and severe disease by nanomedical approaches presents a novel, promising treatment strategy for COVID-19. We anticipate that the use of FDA-approved nanomaterials such as liposomes, PLGA nanoparticles can be used to encapsulate drug molecules that can modulate signal cascades like STAT3 siRNA, NF$\kappa \mathrm{B}$ inhibitor parthenolide, PI3K/mTOR dual inhibitor BEZ235, TGF- $\beta$ inhibitor LY364947, Notch inhibitor dibenzazepine $(\gamma$ secretase inhibitor) will help achieve their long-term circulation and sustained release. The possibility of co-delivery of multiple drugs that nanodelivery systems offers is also of interest, for the improved targeting of the aberrant signal cascades thus attaining a better treatment efficiency and with minimal/no adverse effects, ultimately curbing the hyperinflammation and severe disease in COVID-19. This approach however, necessitates a thorough study; it should not interfere with the protective host immune response or with the viral clearance mechanism of the host. In conclusion, as we enter into the second year of the COVID-19 pandemic with an improved understanding of SARS-CoV-2 and the COVID-19 disease, we surmise that nanomedicine and nanodelivery systems present a more effective approach to dealing with SARS-CoV-2 and associated disease. In particular, the nanomedical targeting of aberrant signaling cascades like JAK/STAT, NF- $\mathrm{B}, \mathrm{PI} 3 \mathrm{~K} / \mathrm{AkT}$, AMPK/ERK, TGF beta, Notch observed in severe COVID-19 disease is a novel approach that is worth exploring and holds great promise.

\section{AUTHOR CONTRIBUTIONS}

AEP: conceptualization and writing of the manuscript. BVS, BGR, and VLK: helped supervise the manuscript. All authors: read and approved the final version of the manuscript.

\section{ACKNOWLEDGMENTS}

The authors wish to acknowledge Andhra University for providing the necessary facilities. We also acknowledge the technical assistance provided by Ms. Susanna R. Peter toward editing the article. analyzing the biodistribution of nanoparticles. Front. Pharmacol. 9:802. doi: 10.3389/fphar.2018.00802

Ashrafizadeh, M., Ahmadi, Z., Kotla, N. G., Afshar, E. G., Samarghandian, S., Mandegary, A., et al. (2019). Nanoparticles targeting STATs in cancer therapy. Cells 8:1158. doi: 10.3390/cells8101158

Astuti, I., and Ysrafil. (2020). Severe acute respiratory syndrome coronavirus 2 (SARS-CoV-2): an overview of viral structure and host response. Diabetes Metab. Syndr. 14, 407-412. doi: 10.1016/j.dsx.2020.04.020

Au, K. M., Wang, A. Z., and Park, S. I. (2020). Pretargeted delivery of PI3K/mTOR small-molecule inhibitor-loaded nanoparticles for treatment of non-Hodgkin's lymphoma. Sci. Adv. 6:eaaz9798. doi: 10.1126/sciadv.aaz9798

Ayres, J. S. (2020). A metabolic handbook for the COVID-19 pandemic. Nat. Metab. 2, 572-585. doi: 10.1038/s42255-020-0237-2

Azar, W. S., Njeim, R., Fares, A. H., Azar, N. S., Azar, S. T., El Sayed, M., et al. (2020). COVID-19 and diabetes mellitus: how one pandemic worsens the other. Rev. Endocr. Metab. Disord. 21, 51-463. doi: 10.1007/s11154-020-09573-6 
Azkur, A. K., Akdis, M., Azkur, D., Sokolowska, M., van de Veen, W., Brüggen, M. C., et al. (2020). Immune response to SARS-CoV-2 and mechanisms of immunopathological changes in COVID-19. Allergy 75, 1564-1581. doi: 10.1111/all.14364

Babazada, H., Yamashita, F., Yanamoto, S., and Hashida, M. (2014). Selfassembling lipid modified glycol-split heparin nanoparticles suppress lipopolysaccharide-induced inflammation through TLR4-NF-kappaB signaling. J. Control. Release 194, 332-340. doi: 10.1016/j.jconrel.2014.09.011

Balagna, C., Perero, S., Percivalle, E., Nepita, E. V., and Ferraris, M. (2020). Virucidal effect against Coronavirus SARS-CoV-2 of a silver nanocluster/silica composite sputtered coating. Open Ceramics 6:100006. doi: 10.1016/j.oceram.2020.100006

Basu, S., Harfouche, R., Soni, S., Chimote, G., Mashelkar, R. A., and Sengupta, S. (2009). Nanoparticle-mediated targeting of MAPK signaling predisposes tumor to chemotherapy. Proc. Natl. Acad. Sci. U.S.A. 106, 7957-7961. doi: 10.1073/pnas.0902857106

Battagello, D. S., Dragunas, G., Klein, M. O., Ayub, A. L. P., Velloso, F. J., and Correa, R. G. (2020). Unpuzzling COVID-19: tissue-related signaling pathways associated with SARS-CoV-2 infection and transmission. Clin. Sci. 134, 2137-2160. doi: 10.1042/CS20200904

Berg, J. M., Tymoczko, J. L., and Stryer, L. (2002a). "Defects in signaling pathways can lead to cancer and other diseases," in Biochemistry, 5th Edn. (New York, NY: W H Freeman). Available online at: https://www.ncbi.nlm.nih.gov/books/ NBK22359/

Berg, J. M., Tymoczko, J. L., and Stryer, L. (2002b). "Signal-transduction pathways: an introduction to information metabolism," in Biochemistry, 5th Edn. (New York, NY: W H Freeman). Available online at: https://www.ncbi.nlm.nih.gov/ books/NBK21205/

Bhavana, V., Thakor, P., Singh, S. B., and Mehra, N. K. (2020). COVID19: pathophysiology, treatment options, nanotechnology approaches, and research agenda to combating the SARS-CoV2 pandemic. Life Sci. 261:118336. doi: 10.1016/j.lfs.2020.118336

Bierie, B., and Moses, H. L. (2010). Transforming growth factor beta (TGFbeta) and inflammation in cancer. Cytokine Growth Factor Rev. 21, 49-59. doi: 10.1016/j.cytogfr.2009.11.008

Bikdeli, B., Madhavan, M. V., Jimenez, D., Chuich, T., Dreyfus, I., Driggin, E., et al. (2020). COVID-19 and thrombotic or thromboembolic disease: implications for prevention, antithrombotic therapy, and follow-up. J. Am. College Cardiol. 75, 2950-2973. doi: 10.1016/j.jacc.2020.04.031

Bi-Wagner, M. J., Mitra, R., McArthur, M. J., Baze, W., Barnhart, K., Wu, S. Y., et al. (2017). Preclinical mammalian safety studies of EPHARNA (DOPC Nanoliposomal EphA2-targeted siRNA). Mol. Cancer Ther. 16, 1114-1123. doi: 10.1158/1535-7163.MCT-16-0541

Bk-Lam, J. K., Chow, M. Y., Zhang, Y., and Leung, S. W. (2015). siRNA Versus miRNA as therapeutics for gene silencing. Mol. Ther. Nucleic Acids 4:e252. doi: $10.1038 / \mathrm{mtna} .2015 .23$

Blanco, E., Sangai, T., Wu, S., Hsiao, A., Ruiz-Esparza, G. U., Gonzalez-Delgado, C. A., et al. (2014). Colocalized delivery of rapamycin and paclitaxel to tumors enhances synergistic targeting of the PI3K/Akt/mTOR pathway. Mol. Ther. 22, 1310-1319. doi: 10.1038/mt.2014.27

Borah, A., Pillai, S. C., Rochani, A. K., Palaninathan, V., Nakajima, Y., Maekawa, T., et al. (2020). GANT61 and curcumin-loaded PLGA nanoparticles for GLI1 and PI3K/Akt-mediated inhibition in breast adenocarcinoma. Nanotechnology 31:185102. doi: 10.1088/1361-6528/ab6d20

Brandão, S. C. S., Ramos, J. O. X., Dompieri, L. T., Godoi, E. T. A. M., Figueiredo, J. L., Sarinho, E. S. C., et al. (2020). Is Toll-like receptor 4 involved in the severity of COVID-19 pathology in patients with cardiometabolic comorbidities? Cytokine Growth Factor Rev. doi: 10.1016/j.cytogfr.2020. 09.002. [Epub ahead of print].

Campos, E. V. R., Pereira, A. E. S., de Oliveira, J. L., Carvalho, L. B., GuilgerCasagrande, M., de Lima, R., et al. (2020). How can nanotechnology help to combat COVID-19? Opportunities and urgent need. J. Nanobiotechnol. 18:125. doi: 10.1186/s12951-020-00685-4

Carsana, L., Sonzogni, A., Nasr, A., Rossi, R. S., Pellegrinelli, A., Zerbi, P., et al. (2020). Pulmonary post-mortem findings in a series of COVID-19 cases from northern Italy: a two-centre descriptive study. Lancet Infect Dis. 20, 1135-1140. doi: 10.1016/S1473-3099(20)30434-5
Cavalcanti, I. D. L., Nogueira, M. C. B. L. (2020). Pharmaceutical nanotechnology: which products are been designed against COVID-19? J. Nanopart. Res. 22:276. doi: 10.1007/s11051-020-05010-6

Chakravarty, M., and Vora, A. (2020). Nanotechnology-based antiviral therapeutics. Drug Del and Transl. Res. 3, 1-40. doi: 10.1007/s13346-020-00818-0

Chauhan, G., Madou, M. J., Kalra, S., Chopra, V., Ghosh, D., and MartinezChapa, S. O. (2020). Nanotechnology for COVID-19: therapeutics and vaccine research. ACS Nano 14, 7760-7782. doi: 10.1021/acsnano.0c04006

Chen, W. (2020). A potential treatment of COVID-19 with TGF- $\beta$ blockade. Int. J. Biol. Sci. 16, 1954-1955. doi: 10.7150/ijbs.46891

Chen, X., Guo, H., Qiu, L., Zhang, C., Deng, Q., and Leng, Q. (2020). Immunomodulatory and antiviral activity of metformin and its potential implications in treating coronavirus disease 2019 and lung injury. Front. Immunol. 11:2056. doi: 10.3389/fimmu.2020.02056

Chen, Y., Zhu, X., Zhang, X., Liu, B., and Huang, L. (2010). Nanoparticles modified with tumor-targeting scFv deliver siRNA and miRNA for cancer therapy. Mol Ther. 18, 1650-1656. doi: 10.1038/mt.2010.136

Chernyak, B. V., Popova, E. N., Zinovkina, L. A., Lyamzaev, K. G., and Zinovkin, R. A. (2020). Mitochondria as targets for endothelial protection in COVID-19. Front. Physiol. 11:606170. doi: 10.3389/fphys.2020.606170

Chiu, H. W., Xia, T., Lee, Y. H., Chen, C. W., Tsai, J. C., and Wang, Y. J. (2015). Cationic polystyrene nanospheres induce autophagic cell death through the induction of endoplasmic reticulum stress. Nanoscale 7, 736-746. doi: $10.1039 / \mathrm{C} 4 \mathrm{NR} 05509 \mathrm{H}$

Colantuoni, A., Martini, R., Caprari, P., Ballestri, M., Capecchi, P. L., Gnasso, A., et al. (2020). COVID-19 sepsis and microcirculation dysfunction. Front. Physiol. 11:747. doi: 10.3389/fphys.2020.00747

Contera, S., de la Serna, B. J., and Tetley, T. D. (2020). Biotechnology, nanotechnology and medicine. Emerg. Top. Life Sci. 9:ETLS20200350. doi: 10.1042/ETLS20200350

Cooper, G. M. (2000). "Pathways of intracellular signal transduction," in The Cell: A Molecular Approach, 2nd Edn. (Sunderland, MA: Sinauer Associates). Available online at: https://www.ncbi.nlm.nih.gov/books/NBK9870/

Costela-Ruiz, V. J., Illescas-Montes, R., Puerta-Puerta, J. M., Ruiz, C., and Melguizo-Rodríguez, L. (2020). SARS-CoV-2 infection: the role of cytokines in COVID-19 disease. Cytokine Growth Factor Rev. 54, 62-75. doi: 10.1016/j.cytogfr.2020.06.001

Darwish, N. H. E., Sudha, T., Godugu, K., Bharali, D. J., Elbaz, O., El-Ghaffar, H. A. A., et al. (2019). Novel targeted nano-parthenolide molecule against NF-kB in acute myeloid leukemia. Molecules 24:2103. doi: 10.3390/molecules24112103

Das, J., Das, S., Paul, A., Samadder, A., Bhattacharyya, S. S., and KhudaBukhsh, A. R. (2014). Assessment of drug delivery and anticancer potentials of nanoparticles-loaded siRNA targeting STAT3 in lung cancer, in vitro and in vivo. Toxicol Lett. 225, 454-466. doi: 10.1016/j.toxlet.2014.01.009

De Jong, W. H., and Borm, P. J. (2008). Drug delivery and nanoparticles: applications and hazards. Int. J. Nanomed. 3, 133-149. doi: 10.2147/IJN.S596

Delpino, M. V., and Quarleri, J. (2020). SARS-CoV-2 pathogenesis: imbalance in the renin-angiotensin system favors lung fibrosis. Front. Cell. Infect. Microbiol. 10:340. doi: $10.3389 /$ fcimb. 2020.00340

Deshpande, C. (2020). Thromboembolic findings in COVID-19 autopsies: pulmonary thrombosis or embolism? Ann. Intern. Med. 173, 394-395. doi: $10.7326 / \mathrm{M} 20-3255$

Dhama, K., Khan, S., Tiwari, R., Sircar, S., Bhat, S., Malik, Y. S., et al. (2020). Coronavirus disease 2019-COVID-19. Clin. Microbiol. Rev. 33:e00028-20. doi: 10.20944/preprints202003.0001.v1

Diao, B., Wang, C., Tan, Y., Chen, X., Liu, Y., Ning, L., et al. (2020). Reduction and functional exhaustion of $\mathrm{t}$ cells in patients with coronavirus disease 2019 (COVID-19). Front. Immunol. 11:827. doi: 10.3389/fimmu.2020.00827

Díez-Martínez, R., García-Fernández, E., Manzano, M., Martínez, Á., Domenech, M., Vallet-Regí, M., et al. (2016). Auranofin-loaded nanoparticles as a new therapeutic tool to fight streptococcal infections. Sci. Rep. 6:19525. doi: $10.1038 /$ srep 19525

Earhart, A. P., Holliday, Z. M., Hofmann, H. V., and Schrum, A. G. (2020). Consideration of dornase alfa for the treatment of severe COVID-19 acute respiratory distress syndrome. New Microbes New Infect. 35:100689. doi: 10.1016/j.nmni.2020.100689 
Edalatifard, M., Akhtari, M.,. Salehi, M., Naderi, Z., Jamshidi, A., Mostafaei, S., et al. (2020). Intravenous methylprednisolone pulse as a treatment for hospitalised severe COVID-19 patients: results from a randomized controlled clinical trial. Eur. Respir. J. 56:2002808. doi: 10.1183/13993003.02808-2020

Ehebauer, M., Hayward, P., and Martinez-Arias, A. (2006). Notch signaling pathway. Sci. STKE 2006:cm7. doi: 10.1126/stke. $3642006 \mathrm{~cm} 7$

Esakandari, H., Nabi-Afjadi, M., Fakkari-Afjadi, J., Farahmandian, N., Miresmaeili, S. M., and Bahreini, E. (2020). A comprehensive review of COVID-19 characteristics. Biol. Proced. Online 22:19. doi: 10.1186/s12575-020-00128-2

Evans, R. M., and Lippman, S. M. (2020). Shining light on the COVID-19 pandemic: a vitamin D receptor checkpoint in defense of unregulated wound healing. Cell Metab. 32, 704-709. doi: 10.1016/j.cmet.2020.09.007

Farooqi, F. I., Morgan, R. C., Dhawan, N., Dinh, J., Yatzkan, G., and Michel, G. (2020). Airway hygiene in COVID-19 pneumonia: treatment responses of 3 critically ill cruise ship employees. Am. J. Case Rep. 21:e926596. doi: 10.12659/AJCR.926596

Ferreira-Gomes, M., Kruglov, A., Durek, P., Heinrich, F., Tizian, C., Heinz, G. A., et al. (2020). In severe COVID-19, SARS-CoV-2 induces a chronic, TGF- $\beta$-dominated adaptive immune response. medRxiv [Preprint]. doi: $10.1101 / 2020.09 .04 .20188169$

Foit, L., and Thaxton, C. S. (2016). Synthetic high-density lipoprotein-like nanoparticles potently inhibit cell signaling and production of inflammatory mediators induced by lipopolysaccharide binding Toll-like receptor 4 . Biomaterials 100, 67-75. doi: 10.1016/j.biomaterials.2016.05.021

Frumovitz, M., and Sood, A. K. (2007). Vascular endothelial growth factor (VEGF) pathway as a therapeutic target in gynecologic malignancies. Gynecol. Oncol. 104, 768-778. doi: 10.1016/j.ygyno.2006.10.062

Fujita, T., Liu, J., Myoujin, M., Shimada, S., Ishikawa, Y., and Fujimori, M. (2018). JAK inhibitors to suppress paclitaxel-resistant anaplastic thyroid cancer via IL-6 reduction. J. Clin. Oncol. 36(15_suppl), el8093. doi: 10.1200/JCO.2018.36.15_suppl.e18093

Fung, M., and Babik, J. M. (2020). COVID-19 in immunocompromised hosts: what we know so far. Clin. Infect. Dis. 72, 340-350. doi: 10.1093/cid/ciaa863

Gao, W., Xiong, Y., Li, Q., and Yang, H. (2017). Inhibition of toll-like receptor signaling as a promising therapy for inflammatory diseases: a journey from molecular to nano therapeutics. Front. Physiol. 8:508. doi: 10.3389/fphys.2017.00508

Gao, Y., Chen, Y., Liu, M., Shi, S., and Tian, J. (2020). Impacts of immunosuppression and immunodeficiency on COVID-19: a systematic review and meta-analysis. J. Infect. 81, e93-e95. doi: 10.1016/j.jinf.2020.05.017

García-Pinel, B., Porras-Alcalá, C., Ortega-Rodríguez, A., Sarabia, F., Prados, J., Melguizo, C., et al. (2019). Lipid-based nanoparticles: application and recent advances in cancer treatment. Nanomaterials 9:638. doi: 10.3390/nano9040638

Gavriatopoulou, M., Korompoki, E., Fotiou, D., Ntanasis-Stathopoulos, I., Psaltopoulou, T., Kastritis, E., et al. (2020). Organ-specific manifestations of COVID-19 infection. Clin. Exp. Med. 20, 493-506. doi: 10.1007/s10238-020-00648-x

Gevers, S., Kwa, M. S. G., Wijnans, E., and van Nieuwkoop, C. (2020). Safety considerations for chloroquine and hydroxychloroquine in the treatment of COVID-19. Clin. Microbiol. Infect. 26:9. doi: 10.1016/j.cmi.2020.05.006

Ghaffari, M., Mollazadeh-Bajestani, M., Moztarzadeh, F., Uludag, H., Hardy, J. G., and Mozafari, M. (2021). An overview of the use of biomaterials, nanotechnology, and stem cells for detection and treatment of COVID-19: towards a framework to address future global pandemics. Emerg. Mater. 2021, 1-16. doi: 10.1007/s42247-020-00143-9

Ghasemnejad-Berenji, M., and Pashapour, S. (2020). SARS-CoV-2 and the possible role of Raf/MEK/ERK pathway in viral survival: is this a potential therapeutic strategy for COVID-19? Pharmacology 2, 1-3. doi: 10.1159/000511280

Giamarellos-Bourboulis, E. J., Netea, M. G., Rovina, N., Akinosoglou, K., Antoniadou, A., Antonakos, N., et al. (2020). Complex immune dysregulation in COVID-19 patients with severe respiratory failure. Cell Host Microbe 27, 992-1000.e3. doi: 10.1016/j.chom.2020.04.009

Grimes, J. M., and Grimes, K. V. (2020). p38 MAPK inhibition: a promising therapeutic approach for COVID-19. J. Mol. Cell Cardiol. 144, 63-65. doi: 10.1016/j.yjmcc.2020.05.007

Guan, W. J., Liang, W. H., Zhao, Y., Liang, H. R., Chen, Z. S., Li, Y. M., et al. (2020). China medical treatment expert group for COVID-19. comorbidity and its impact on 1590 patients with COVID-19 in China: a nationwide analysis. Eur. Respir. J. 55:2000547. doi: 10.1183/13993003.01227-2020

Guihot, A., Litvinova, E., Autran, B., Debré, P., and Vieillard, V. (2020). Cellmediated immune responses to COVID-19 infection. Front. Immunol. 11:1662. doi: 10.3389/fimmu.2020.01662

Guo, Y. J., Pan, W. W., Liu, S. B., Shen, Z. F., Xu, Y., and Hu, L. L. (2020). ERK/MAPK signalling pathway and tumorigenesis. Exp. Ther. Med. 19, 1997-2007. doi: 10.3892/etm.2020.8454

Hadjadj, J., Yatim, N., Barnabei, L., Corneau, A., Boussier, J., Smith, N., et al. (2020). Impaired type I interferon activity and inflammatory responses in severe COVID-19 patients. Science 369, 718-724. doi: 10.1126/science.abc6027

Halazy, S. (2003). Signal transduction: an exciting field of investigation for small molecule drug discovery. Molecules 8, 349-358. doi: 10.3390/80400349

Han, J., Zhao, D., Li, D., Wang, X., Jin, Z., and Zhao, K. (2018). Polymerbased nanomaterials and applications for vaccines and drugs. Polymers 10:31. doi: 10.3390/polym10010031

Hariharan, A., Hakeem, A. R., Radhakrishnan, S., Reddy, M. S., and Rela, M. (2020). The role and therapeutic potential of NF-kappa-B pathway in severe COVID-19 patients. Inflammopharmacology. 29:91-100. doi: $10.1007 /$ s10787-020-00773-9

Harrison, D. A. (2012). The JAK/STAT pathway. Cold Spring Harb. Perspect. Biol. 4:a011205. doi: 10.1101/cshperspect.a011205

Harrison, S. L., Fazio-Eynullayeva, E., Lane, D. A., Underhill, P., and Lip, G. Y. H. (2020). Comorbidities associated with mortality in 31,461 adults with COVID19 in the United States: a federated electronic medical record analysis. PLoS Med. 17:e1003321. doi: 10.1371/journal.pmed.1003321

Hattori, Y., Kikuchi, T., Nakamura, M., Ozaki, K. I., and Onishi, H. (2017). Therapeutic effects of protein kinase N3 small interfering RNA and doxorubicin combination therapy on liver and lung metastases. Oncol. Lett. 14, 5157-5166. doi: 10.3892/ol.2017.6830

Hawthorne, G. H., Bernuci, M. P., Bortolanza, M., Issy, A. C., and Del-Bel, E. (2017). "Clinical developments in antimicrobial nanomedicine: toward novel solutions," in In Micro and Nano Technologies, Nanostructures for Antimicrobial Therapy, eds A. Ficai and A. M. Grumezescu (Elsevier), 653-668.

He, F., Deng, Y., and Li, W. (2020). Coronavirus disease 2019: what we know? J. Med. Virol. 92, 719-725. doi: 10.1002/jmv.25766

Hildebrand, D., Uhle, F., Sahin, D., Krauser, U., Weigand, M. A., and Heeg, K. (2018). The interplay of notch signaling and STAT3 in TLRactivated human primary monocytes. Front. Cell Infect. Microbiol. 8:241. doi: 10.3389/fcimb.2018.00241

Hou, X., Zhang, X., Wu, X., Lu, M., Wang, D., Xu, M., et al. (2020). Serum protein profiling reveals a landscape of inflammation and immune signaling in early-stage COVID-19 infection. Mol. Cell Proteomics 19, 1749-1759. doi: 10.1074/mcp.RP120.002128

Hui-Hui, G., Chen-Lin, F., Wen-Xuan, Z., Zhi-Gang, L., Hong-Juan, Z., Ting-Ting, T., et al. (2019). Liver-target nanotechnology facilitates berberine to ameliorate cardio-metabolic diseases. Nat. Commun. 10:1981. doi: 10.1038/s41467-019-09852-0

Husain, A., and Byrareddy, S. N. (2020). Rapamycin as a potential repurpose drug candidate for the treatment of COVID-19. Chem. Biol. Interact. 331:109282. doi: $10.1016 /$ j.cbi.2020.109282

Icard, P., Lincet, H., Wu, Z., Coquerel, A., Forgez, P., Alifano, M., et al. (2020). The key role of Warburg effect in SARS-CoV-2 replication and associated inflammatory response. Biochimie 180, 169-177. doi: 10.1016/j.biochi.2020.11.010

Inamdar, G. S., Madhunapantula, S. V., and Robertson, G. P. (2010). Targeting the MAPK pathway in melanoma: why some approaches succeed and other fail. Biochem. Pharmacol. 80, 624-637. doi: 10.1016/j.bcp.2010.04.029

Iqbal, H. (2020). The importance of cell-mediated immunity in COVID19 - an opinion. Med. Hypotheses 143:110152. doi: 10.1016/j.mehy.2020. 110152

Islam, A. B. M. M. K., and Khan, M. A. A. K. (2020). Lung transcriptome of a COVID-19 patient and systems biology predictions suggest impaired surfactant production which may be druggable by surfactant therapy. Sci. Rep. 10:19395. doi: 10.1038/s41598-020-76404-8

Jacques, F. H., and Apedaile, E. (2020). Immunopathogenesis of COVID19: summary and possible interventions. Front. Immunol. 11:564925. doi: $10.3389 /$ fimmu. 2020.564925 
Jeon, S. M. (2016). Regulation and function of AMPK in physiology and diseases. Exp. Mol. Med. 48:e245. doi: 10.1038/emm.2016.81

Jiang, C., Cano-Vega, M. A., Yue, F., Kuang, L., Narayanan, N., Uzunalli, G., et al. (2017). Dibenzazepine-loaded nanoparticles induce local browning of white adipose tissue to counteract obesity. Mol. Ther. 25, 1718-1729. doi: 10.1016/j.ymthe.2017.05.020

Jiang, Q., Dai, L., Cheng, L., Chen, X., Li, Y., Zhang, S., et al. (2013). Efficient inhibition of intraperitoneal ovarian cancer growth in nude mice by liposomal delivery of short hairpin RNA against STAT 3. J. Obstet. Gynaecol. Res. 39, 701-709. doi: 10.1111/j.1447-0756.2012.02007.x

Jin, Y., Ji, W., Yang, H., Chen, S., Zhang, W., and Duan, G. (2020). Endothelial activation and dysfunction in COVID-19: from basic mechanisms to potential therapeutic approaches. Signal. Transduct. Target Ther. 5:293. doi: 10.1038/s41392-020-00454-7

Jindal, S., and Gopinath, P. (2020). Nanotechnology based approaches for combating COVID-19 viral infection. Nano Express 1. doi: 10.1088/2632-959X/abb714

Jones, G. W., Monopoli, M. P., Campagnolo, L., Pietroiusti, A., Tran, L., and Fadeel, B. (2020). No small matter: a perspective on nanotechnologyenabled solutions to fight COVID-19. Nanomedicine 15, 2411-2427. doi: $10.2217 / \mathrm{nnm}-2020-0286$

Kawasaki, T., and Kawai, T. (2014). Toll-like receptor signaling pathways. Front. Immunol. 5:461. doi: 10.3389/fimmu.2014.00461

Khan, M. A., Khan, Z. A., Charles, M., Pratap, P., Naeem, A., Siddiqui, Z., et al. (2021). Cytokine storm and mucus hypersecretion in COVID-19: review of mechanisms. J. Inflamm. Res. 14, 175-189. doi: 10.2147/JIR.S271292

Khan, M. I., Mohammad, A., Patil, G., Naqvi, S. A., Chauhan, L. K., and Ahmad, I. (2012). Induction of ROS, mitochondrial damage and autophagy in lung epithelial cancer cells by iron oxide nanoparticles. Biomaterials 33, 1477-1488. doi: 10.1016/j.biomaterials.2011.10.080

Kim, W. J., Yockman, J. W., Jeong, J. H., Christensen, L. V., Lee, M., Kim, Y. H., et al. (2006). Anti-angiogenic inhibition of tumor growth by systemic delivery of PEI-g-PEG-RGD/pCMV-sFlt-1 complexes in tumor-bearing mice. J. Control. Release 114, 381-388. doi: 10.1016/j.jconrel.2006.05.029

Koch, S., and Claesson-Welsh, L. (2012). Signal transduction by vascular endothelial growth factor receptors. Cold Spring Harb. Perspect. Med. 2:a006502. doi: 10.1101/cshperspect.a006502

Kopan, R. (2012). Notch signaling. Cold Spring Harb. Perspect. Biol. 4:a011213. doi: $10.1101 /$ cshperspect.a011213

Labala, S., Jose, A., Chawla, S. R., Khan, M. S., Bhatnagar, S., Kulkarni, O. P., et al. (2017). Effective melanoma cancer suppression by iontophoretic codelivery of STAT3 siRNA and imatinib using gold nanoparticles. Int. J. Pharm. 525,407-417. doi: 10.1016/j.ijpharm.2017.03.087

Laplante, M., and Sabatini, D. M. (2012a). mTOR signaling in growth control and disease. Cell 149, 274-293. doi: 10.1016/j.cell.2012.03.017

Laplante, M., and Sabatini, D. M. (2012b). mTOR signaling. Cold Spring Harb. Perspect. Biol. 4:a011593. doi: 10.1101/cshperspect.a011593

Lavado, R. J., Sestito, S. E., Cighetti, R., Moncayo, A. E. M., Oblak, A., Lainšček, D., et al. (2014). Trehalose- and glucose-derived glycoamphiphiles: small-molecule and nanoparticle Toll-like receptor 4 (TLR4) modulators. J. Med. Chem. 57, 9105-9123. doi: 10.1021/jm501182w

Lax, S. F., Skok, K., Zechner, P., Kessler, H. H., Kaufmann, N., Koelblinger, C., et al. (2020). Pulmonary arterial thrombosis in COVID-19 with fatal outcome: results from a prospective, single-center, clinicopathologic case series. Ann. Intern. Med. 173, 350-361. doi: 10.7326/M20-2566

Lee, K. S., Chung, H. C., Im, S. A., Park, Y. H., Kim, C. S., Kim, S. B., et al. (2008). Multicenter phase II trial of Genexol-PM, a Cremophor-free, polymeric micelle formulation of paclitaxel, in patients with metastatic breast cancer. Breast Cancer Res. Treat. 108, 241-250. doi: 10.1007/s10549-007-9591-y

Li, D., Chen, Y., Liu, H., Jia, Y., Li, F., Wang, W., et al. (2020). Immune dysfunction leads to mortality and organ injury in patients with COVID-19 in China: insights from ERS-COVID-19 study. Signa.l Transduct. Target Ther. 5:62. doi: 10.1038/s41392-020-0163-5

Li, H., Liu, S. M., Yu, X. H., Tang, S. L., and Tang, C. K. (2020). Coronavirus disease 2019 (COVID-19): current status and future perspectives. Int. J. Antimicrob. Agents. 55:105951. doi: 10.1016/j.ijantimicag.2020.1 05951
Liu, Y., Lv, J., Liu, J., Li, M., Xie, J., Lv, Q., et al. (2020). Mucus production stimulated by IFN-AhR signaling triggers hypoxia of COVID-19. Cell Res. 30, 1078-1087. doi: 10.1038/s41422-020-00435-Z

Liu, Y., Yu, H., Zhang, X., Wang, Y., Song, Z., Zhao, J., et al. (2018). The protective role of autophagy in nephrotoxicity induced by bismuth nanoparticles through AMPK/mTOR pathway. Nanotoxicology 12, 586-601. doi: $10.1080 / 17435390.2018 .1466932$

Loos, C., Syrovets, T., Musyanovych, A., Mailänder, V., Landfester, K., and Simmet, T. (2014). Amino-functionalized nanoparticles as inhibitors of mTOR and inducers of cell cycle arrest in leukemia cells. Biomaterials 35, 1944-1953. doi: 10.1016/j.biomaterials.2013.11.056

Lotfi, M., Hamblin, M. R., and Rezaei, N. (2020). COVID-19: Transmission, prevention, and potential therapeutic opportunities. Clin. Chim. Acta 508, 254-266. doi: 10.1016/j.cca.2020.05.044

Lu, B., Huang, X., Mo, J., and Zhao, W. (2016). Drug delivery using nanoparticles for cancer stem-like cell targeting. Front. Pharmacol. 7:84. doi: 10.3389/fphar.2016.00084

Lu, W., Liu, X., Wang, T., Liu, F., Zhu, A., Lin, Y., et al. (2021). Elevated MUC1 and MUC5AC mucin protein levels in airway mucus of critical ill COVID-19 patients. J. Med. Virol. 93, 582-584. doi: 10.1002/jmv.26406

Lunova, M., Smolková, B., Lynnyk, A., Uzhytchak, M., Jirsa, M., Kubinová, Š., et al. (2019). Targeting the mTOR signaling pathway utilizing nanoparticles: a critical overview. Cancers 11:82. doi: 10.3390/cancers11010082

Luo, L., Fu, M., Li, Y., Hu, S., Luo, J., Chen, Z., et al. (2020). The potential association between common comorbidities and severity and mortality of coronavirus disease 2019: a pooled analysis. Clin. Cardiol. 43, 1478-1493. doi: $10.1002 / \mathrm{clc} .23465$

Luo, W., Li, Y. X., Jiang, L. J., Chen, Q., Wang, T., and Ye, D. W. (2020). Targeting JAK-STAT signaling to control cytokine release syndrome in COVID-19. Trends Pharmacol. Sci. 41, 531-543. doi: 10.1016/j.tips.2020.06.007

Luo, Z., Wang, C., Yi, H., Li, P., Pan, H., Liu, L., et al. (2015). Nanovaccine loaded with poly I:C and STAT3 siRNA robustly elicits anti-tumor immune responses through modulating tumor-associated dendritic cells in vivo. Biomaterials 38, 50-60. doi: 10.1016/j.biomaterials.2014.10.050

Maher, D. M., Bell, M. C., O’Donnell, E. A., Gupta, B. K., Jaggi, M., and Chauhan, S. C. (2011). Curcumin suppresses human papillomavirus oncoproteins, restores $\mathrm{p} 53, \mathrm{Rb}$, and PTPN13 proteins and inhibits benzo[a]pyrene-induced upregulation of HPV E7. Mol. Carcinog. 50, 47-57. doi: 10.1002/mc.20695

Mahmoud, N. N., Abuarqoub, D., Zaza, R., Sabbah, D. A., Khalil, E. A., and Abu-Dahab, R. (2020). Gold nanocomplex strongly modulates the PI3K/Akt pathway and other pathways in MCF-7 breast cancer cell line. Int. J. Mol. Sci. 21:3320. doi: 10.3390/ijms21093320

Maiese, K. (2020). The mechanistic target of rapamycin (mTOR): novel considerations as an antiviral treatment. Curr. Neurovasc. Res. 17, 332-337. doi: 10.2174/1567202617666200425205122

Mainardes, R. M., and Diedrich, C. (2020). The potential role of nanomedicine on COVID-19 therapeutics. Ther Del. 11, 411-414. doi: 10.4155/tde-2020-0069

Mamaeva, V., Niemi, R., Beck, M., Özliseli, E., Desai, D., Landor, S., et al. (2016). Inhibiting Notch activity in breast cancer stem cells by glucose functionalized nanoparticles carrying $\gamma$-secretase inhibitors. Mol. Ther. 24, 926-936. doi: 10.1038/mt.2016.42

Mamaeva, V., Rosenholm, J. M., Bate-Eya, L. T., Bergman, L., Peuhu, E., Duchanoy, A., et al. (2011). Mesoporous silica nanoparticles as drug delivery systems for targeted inhibition of Notch signaling in cancer. Mol. Ther. 19, 1538-1546. doi: 10.1038/mt.2011.105

Massabeti, R., Cipriani, M. S., and Valenti, I. (2020). COVID-19: a systemic disease treated with a wide-ranging approach: a case report. J. Popul. Ther. Clin. Pharmacol. 27, e26-e30. doi: 10.15586/jptcp.v27iSP1.691

Matsuyama, T., Kubli, S. P., Yoshinaga, S. K., Pfeffer, K., and Mak, T. W. (2020). An aberrant STAT pathway is central to COVID-19. Cell Death Differ. 27, 3209-3225. doi: 10.1038/s41418-020-00633-7

Mehraeen, E., Karimi, A., Barzegary, A., Vahedi, F., Afsahi, A. M., Dadras, O., et al. (2020). Predictors of mortality in patients with COVID-19-a systematic review. Eur. J. Integr. Med. 40:101226. doi: 10.1016/j.eujim.2020.101226

Meini, S., Giani, T., and Tascini, C. (2020). Intussusceptive angiogenesis in COVID-19: hypothesis on the significance and focus on the possible role of FGF2. Mol. Biol. Rep. 47, 8301-8304. doi: 10.1007/s11033-020-05831-7 
Meng, H., Zhao, Y., Dong, J., Xue, M., Lin, Y. S., Ji, Z., et al. (2013). Twowave nanotherapy to target the stroma and optimize gemcitabine delivery to a human pancreatic cancer model in mice. ACS Nano 7, 10048-10065. doi: $10.1021 / \mathrm{nn} 404083 \mathrm{~m}$

Menter, T., Haslbauer, J. D., Nienhold, R., Savic, S., Hopfer, H., Deigendesch, N., et al. (2020). Postmortem examination of COVID-19 patients reveals diffuse alveolar damage with severe capillary congestion and variegated findings in lungs and other organs suggesting vascular dysfunction. Histopathology 77, 198-209. doi: 10.1111/his.14134

Merad, M., and Martin, J. C. (2020). Pathological inflammation in patients with COVID-19: a key role for monocytes and macrophages. Nat. Rev. Immunol. 20, 355-362. doi: 10.1038/s41577-020-0331-4

Mihaylova, M. M., and Shaw, R. J. (2011). The AMPK signalling pathway coordinates cell growth, autophagy and metabolism. Nat. Cell Biol. 13, 1016-1023. doi: 10.1038/ncb2329

Mimeault, M., and Batra, S. K. (2011). Potential applications of curcumin and its novel synthetic analogs and nanotechnology-based formulations in cancer prevention and therapy. Chin. Med. 6:31. doi: 10.1186/1749-8546-6-31

Mizrachi, A., Shamay, Y., Shah, J., Brook, S., Soong, J., Rajasekhar, V. K., et al. (2017). Tumour-specific PI3K inhibition via nanoparticle-targeted delivery in head and neck squamous cell carcinoma. Nat. Commun. 8:14292. doi: $10.1038 /$ ncomms14292

Mora-Garcia, P., and Sakamoto, K. M. (1999). Cell signaling defects and human disease. Mol. Genet. Metab. 66, 143-171. doi: 10.1006/mgme.1998.2798

Mortaz, E., Tabarsi, P., Varahram, M., Folkerts, G., and Adcock, I. M. (2020). The immune response and immunopathology of COVID-19. Front. Immunol. 11:2037. doi: 10.3389/fimmu.2020.02037

Moutal, A., Martin, L. F., Boinon, L., Gomez, K., Ran, D., Zhou, Y., et al. (2020). SARS-CoV-2 spike protein co-opts VEGF-A/neuropilin-1 receptor signaling to induce analgesia. Pain 162, 243-252. doi: 10.1097/j.pain.0000000000002097

Mukerjee, A., and Vishwanatha, J. K. (2009). Formulation, characterization and evaluation of curcumin-loaded PLGA nanospheres for cancer therapy. Anticancer Res. 29, 3867-3875.

Mukherjee, P., Bhattacharya, R., Bone, N., Lee, Y. K., Patra, C. R., Wang, S., et al. (2007). Potential therapeutic application of gold nanoparticles in B-chronic lymphocytic leukemia (BCLL): enhancing apoptosis. J. Nanobiotechnol. 5:4. doi: 10.1186/1477-3155-5-4

Munjal, M., Das, S., Chatterjee, N., Setra, A. E., and Govil, D. (2020). Systemic involvement of novel coronavirus (COVID-19): a review of literature. Indian J. Crit. Care Med. 24, 565-569. doi: 10.5005/jp-journals-10071-23498

Muthuraman, A., Rishitha, N., and Mehdi, S. (2018). "Role of nanoparticles in bioimaging, diagnosis and treatment of cancer disorder," in Design of Nanostructures for Theranostics Applications, ed A. M. Grumezescu (Norwich, NY: William Andrew Publishing), 529-562.

Nanomedicine and the COVID-19 vaccines (2020). Nat. Nanotechnol. 15:963. doi: 10.1038/s41565-020-00820-0

Nikolova, M. P., and Chavali, M. S. (2020). Metal oxide nanoparticles as biomedical materials. Biomimetics 5:27. doi: 10.3390/biomimetics5020027

Nils, C. G., Papies, J., Thomas, B., Frederik, D., Jackson, E., Katja, W., et al. (2020). Analysis of SARS-CoV-2-controlled autophagy reveals spermidine, MK-2206, and niclosamide as putative antiviral therapeutics. bioRxiv [Preprint].

O’Dea, E., and Hoffmann, A. (2009). NF-кB signaling. Wiley Interdiscip. Rev. Syst. Biol. Med. 1, 107-115. doi: 10.1002/wsbm.30

Onofrio, L., Caraglia, M., Facchini, G., Margherita, V., Placido, S., and Buonerba, C. (2020). Toll-like receptors and COVID-19: a two-faced story with an exciting ending. Future Sci. OA. 6:FSO605. doi: 10.2144/fsoa-2020-0091

Ortega, R. A., Barham, W., Sharman, K., Tikhomirov, O., Giorgio, T. D., and Yull, F. E. (2016). Manipulating the NF- $\kappa B$ pathway in macrophages using mannosylated, siRNA-delivering nanoparticles can induce immunostimulatory and tumor cytotoxic functions. Int. J. Nanomed. 11, 2163-2177. doi: $10.2147 /$ IJN.S93483

Orza, A. (2015). Targeting the Notch signaling pathways of hepatocarcinoma and glioblastoma multiform using ultra small iron oxide nanoparticles conjuagated gamma secretase inhibitor. Clin. Exp. Pharmacol. 5:4.

Ouassou, H., Kharchoufa, L., Bouhrim, M., Daoudi, N. E., Imtara, H., Bencheikh, N., et al. (2020). The pathogenesis of coronavirus disease 2019 (COVID-19): evaluation and prevention. J. Immunol. Res. 2020:1357983. doi: $10.1155 / 2020 / 1357983$
Palestino, G., Garcia-Silva, I., Gonzalez-Ortega, O., and Rosales-Mendoza, S. (2020). Can nanotechnology help in the fight against COVID-19? Expert Rev. Anti Infect Ther. 18, 849-864, doi: 10.1080/14787210.2020.1776115

Pang, J., Xu, F., Aondio, G., Li, Y., Fumagalli, A., Lu, M., et al. (2021). Efficacy and tolerability of bevacizumab in patients with severe COVID-19. Nat. Commun. 12:814. doi: 10.1038/s41467-021-21085-8

Parasher, A. (2020). COVID-19: Current understanding of its pathophysiology, clinical presentation and treatment. Postgrad. Med. J. doi: 10.1136/postgradmedj-2020-138577. [Epub ahead of print].

Patra, R., Chandra Das, N., and Mukherjee, S. (2021). Targeting human TLRs to combat COVID-19: a solution? J. Med. Virol. 93, 615-617. doi: $10.1002 / j m v .26387$

Pedersen, S. F., and Ho, Y. C. (2020). SARS-CoV-2: a storm is raging. J. Clin. Invest. 130, 2202-2205. doi: 10.1172/JCI137647

Perico, L., Benigni, A., Casiraghi, F., Ng, L. F. P., Renia, L., and Remuzzi, G. (2020). Immunity, endothelial injury and complement-induced coagulopathy in COVID-19. Nat. Rev. Nephrol. 17, 46-64. doi: 10.1038/s41581-020-00357-4

Peter, A. E., Sandeep, B. V., Rao, B. G., and Kalpana, V. L. (2021). Calming the storm: natural immunosuppressants as adjuvants to target the cytokine storm in COVID-19. Front. Pharmacol. 11:583777. doi: 10.3389/fphar.2020.583777

Piñón-Segundo, E., Mendoza-Muñoz, N., and Quintanar-Guerrero, D. (2013). "Nanoparticles as dental drug-delivery systems," in Nanobiomaterials in Clinical Dentistry, eds K. Subramani, W. Ahmed, and J. K. Hartsfield (Norwich, NY: William Andrew Publishing), 475-495.

Posso, M., Comas, M., Román, M., Domingo, L., Louro, J., González, C., et al. (2020). Comorbidities and mortality in patients with COVID-19 aged 60 years and older in a University Hospital in Spain. Arch. Bronconeumol. 56, 756-758. doi: 10.1016/j.arbres.2020.06.012

Prasad, M., Lambe, U. P., Brar, B., Shah, I., Manimegalai, J., Ranjan, K., et al. (2018). Nanotherapeutics: an insight into healthcare and multi-dimensional applications in medical sector of the modern world. Biomed. Pharmacother. 97, 1521-1537. doi: 10.1016/j.biopha.2017.11.026

Praveen, T., Desai, D., Soneja, M., and Wig, N. (2020). Immune dysregulation in COVID-19 and its therapeutic implications. J. Clin. Sci.Res. 9, 37-41. doi: 10.4103/JCSR.JCSR_40_20

Prompetchara, E., Ketloy, C., and Palaga, T. (2020). Immune responses in COVID19 and potential vaccines: lessons learned from SARS and MERS epidemic. Asian Pac. J. Allergy Immunol. 38, 1-9. doi: 10.12932/AP-200220-0772

Qin, C., Zhou, l., Hu, Z., Zhang, S., Yang, S., Tao, Y., et al. (2020). Dysregulation of immune response in patients with coronavirus 2019 (COVID-19) in Wuhan, China. Clin. Infect. Dis. 71, 762-768. doi: 10.1093/cid/ciaa248

Rabaan, A. A., Al-Ahmed, S. H., Sah, R., Tiwari, R., Yatoo, M. I., Patel, S. K., et al. (2020). SARS-CoV-2/COVID-19 and advances in developing potential therapeutics and vaccines to counter this emerging pandemic. Ann. Clin. Microbiol. Antimicrob. 19:40. doi: 10.1186/s12941-02000384-w

Rai, M., Bonde, S., Yadav, A., Plekhanova, Y., Reshetilov, A., Gupta, I., et al. (2020). Nanotechnology-based promising strategies for the management of COVID19: current development and constraints. Expert Rev. Anti Infect Ther. 8:1-10. doi: $10.1080 / 14787210.2021 .1836961$

Ramaiah, M. J. (2020). mTOR inhibition and p53 activation, microRNAs: the possible therapy against pandemic COVID-19. Gene Rep. 20:100765. doi: 10.1016/j.genrep.2020.100765

Reiken, S., Dridi, H., Sittenfeld, L., Liu, X., and Marks, A. R. (2021). Alzheimer'slike remodeling of neuronal ryanodine receptor in COVID-19. bioRxiv [Preprint]. doi: 10.1101/2021.02.18.431811

Ren, X., Zhao, B., Chang, H., Xiao, M., Wu, Y., and Liu, Y. (2018). Paclitaxel suppresses proliferation and induces apoptosis through regulation of ROS and the AKT/MAPK signaling pathway in canine mammary gland tumor cells. Mol. Med. Rep. 17, 8289-8299. doi: 10.3892/mmr.2018.8868

Riehemann, K., Schneider, S. W., Luger, T. A., Godin, B., Ferrari, M., and Fuchs, H. (2009). Nanomedicine-challenge and perspectives. Angew. Chem. Int. Ed. Engl. 48, 872-897. doi: 10.1002/anie.200802585

Risitano, A. M., Mastellos, D. C., Huber-Lang, M., Yancopoulou, D., Garlanda, C., Ciceri, F., et al. (2020). Complement as a target in COVID-19? Nat. Rev. Immunol. 20, 343-344. doi: 10.1038/s41577-020-0320-7

Rizzo, P., Sega, F. V. D., Fortini, F., Marracino, L., Rapezzi, C., and Ferrari, R. (2020). COVID-19 in the heart and the lungs: could 
we "Notch" the inflammatory storm? Basic Res. Cardiol. 115:31. doi: 10.1007/s00395-020-0791-5

Rosa, B. A., Ahmed, M., Singh, D. K., Choreño-Parra, J. A., Cole, J., JiménezÁlvarez, L. A., et al. (2020). IFN signaling and neutrophil degranulation transcriptional signatures are induced during SARS-CoV-2 infection. Commun Biol. 4:290. doi: 10.1038/s42003-021-01829-4

Rothan, H. A., Stone, S., Natekar, J., Kumari, P., Arora, K., and Kumar, M. (2020). The FDA-approved gold drug auranofin inhibits novel coronavirus (SARS-COV-2) replication and attenuates inflammation in human cells. Virology 547, 7-11. doi: 10.1016/j.virol.2020.05.002

Ruiz-Hitzky, E., Darder, M., Wicklein, B., Ruiz-Garcia, C., Martín-Sampedro, R., Real, G. D., et al. (2020). Nanotechnology responses to COVID-19. Adv. Healthc. Mater. 9:e2000979. doi: 10.1002/adhm.202000979

Ruttala, H. B., and Ko, Y. T. (2015). Liposomal co-delivery of curcumin and albumin/paclitaxel nanoparticle for enhanced synergistic antitumor efficacy. Colloids Surf. B. Biointerfaces 128, 419-426. doi: 10.1016/j.colsurfb.2015.02.040

Santoro, M. G., Rossi, A., and Amici, C. (2003). NF-kappaB and virus infection: who controls whom. EMBO J. 22, 2552-2560. doi: 10.1093/emboj/cdg267

Satarker, S., Tom, A. A., Shaji, R. A., Alosious, A., Luvis, M., and Nampoothiri, M. (2020). JAK-STAT pathway inhibition and their implications in COVID19 therapy. Postgrad. Med. doi: 10.1080/00325481.2020.1855921. [Epub ahead of print].

Schiffelers, R. M., Ansari, A., Xu, J., Zhou, Q., Tang, Q., Storm, G., et al. (2004). Cancer siRNA therapy by tumor selective delivery with ligand-targeted sterically stabilized nanoparticle. Nucleic Acids Res. 32:e149. doi: 10.1093/nar/gnh140

Schmitz, M. L., Kracht, M., and Saul, V. V. (2014). The intricate interplay between RNA viruses and NF-кB. Biochim. Biophys. Acta 1843, 2754-2764. doi: 10.1016/j.bbamcr.2014.08.004

Schultheis, B., Strumberg, D., Santel, A., Vank, C., Gebhardt, F., Keil, O., et al. (2014). First-in-human phase I study of the liposomal RNA interference therapeutic Atu027 in patients with advanced solid tumors. J. Clin. Oncol. 32, 4141-4148. doi: 10.1200/JCO.2013.55.0376

Schurink, B., Roos, E., Radonic, T., Barbe, E., Bouman, C. S. C., de Boer, H. H., et al. (2020). Viral presence and immunopathology in patients with lethal COVID-19: a prospective autopsy cohort study. Lancet Microbe 1, e290-e299. doi: 10.1016/S2666-5247(20)30144-0

Seif, F., Khoshmirsafa, M., Aazami, H., Mohsenzadegan, M., Sedighi, G., and Bahar, M. (2017). The role of JAK-STAT signaling pathway and its regulators in the fate of T helper cells. Cell Commun. Signal. 15:23. doi: 10.1186/s12964-017-0177-y

Shah, S. J., Barish, P. N., Prasad, P. A., Kistler, A., Neff, N., Kamm, J., et al. (2020). Clinical features, diagnostics, and outcomes of patients presenting with acute respiratory illness: a retrospective cohort study of patients with and without COVID-19. EClinicalMedicine. 27:100518. doi: 10.1016/j.eclinm.2020. 100518

Sharma, V., Sharma, A. K., Punj, V., and Priya, P. (2019). Recent nanotechnological interventions targeting PI3K/Akt/mTOR pathway: a focus on breast cancer. Semin. Cancer Biol. 59, 133-146. doi: 10.1016/j.semcancer.2019.08.005

Shibuya, M. (2011). Vascular endothelial growth factor (VEGF) and its receptor (VEGFR) signaling in angiogenesis: a crucial target for anti- and pro-angiogenic therapies. Genes Cancer 2, 1097-1105. doi: $10.1177 / 1947601911423031$

Singh, A. K., and Misra, A. (2020). Impact of COVID-19 and comorbidities on health and economics: focus on developing countries and India. Diabetes Metab. Syndr. 14, 1625-1630. doi: 10.1016/j.dsx.2020.08.032

Singh, D. R., Kanvinde, P., King, C., Pasquale, E. B., and Hristova, K. (2018). The EphA2 receptor is activated through induction of distinct, ligand-dependent oligomeric structures. Commun. Biol. 1:15. doi: 10.1038/s42003-018-0017-7

Soares, S., Sousa, J., Pais, A., and Vitorino, C. (2018). Nanomedicine: principles, properties, and regulatory issues. Front. Chem. 6:360. doi: $10.3389 /$ fchem. 2018.00360

Sohn, K. M., Lee, S. G., Kim, H. J., Cheon, S., Jeong, H., Lee, J., et al. (2020). COVID-19 patients upregulate toll-like receptor 4-mediated inflammatory signaling that mimics bacterial sepsis. J. Korean Med. Sci. 35:e343. doi: 10.3346/jkms.2020.35.e343

Somanath, P. R. (2020). Is targeting Akt a viable option to treat advanced-stage COVID-19 patients? Am. J. Physiol. Lung Cell Mol. Physiol. 319, L45-L47. doi: 10.1152/ajplung.00124.2020
Song, J. W., Zhang, C., Fan, X., Meng, F. P., Xu, Z., Xia, P., et al. (2020). Immunological and inflammatory profiles in mild and severe cases of COVID19. Nat. Commun. 11:3410. doi: 10.1038/s41467-020-17240-2

Sousa, C. P., and Brites, C. (2020). Immune response in SARS-CoV-2 infection: the role of interferons type I and type III. Braz J. Infect. Dis. 24, 428-433. doi: 10.1016/j.bjid.2020.07.011

Stacker, S. A., and Achen, M. G. (2013). The VEGF signaling pathway in cancer: the road ahead. Chin. J. Cancer. 32, 297-302. doi: 10.5732/cjc.012.10319

Stephens, D. S., and McElrath, M. J. (2020). COVID-19 and the path to immunity. JAMA 324, 1279-1281. doi: 10.1001/jama.2020.16656

Sun, D., Liu, Y., Yu, Q., Zhou, Y., Zhang, R., Chen, X., et al. (2013). The effects of luminescent ruthenium(II) polypyridyl functionalized selenium nanoparticles on bFGF-induced angiogenesis and AKT/ERK signaling. Biomaterials 34, 171-180. doi: 10.1016/j.biomaterials.2012.09.031

Sureban, S. M., May, R., Mondalek, F. G., Qu, D., Ponnurangam, S., Pantazis, P., et al. (2011). Nanoparticle-based delivery of siDCAMKL-1 increases microRNA-144 and inhibits colorectal cancer tumor growth via a Notch-1 dependent mechanism. J. Nanobiotechnol. 9:40. doi: 10.1186/1477-3155-9-40

Sutradhra, K. B., and Amin, M. L. (2014). Nanotechnology in cancer drug delivery and selective targeting. Int. Scholarly Res. Notices. 2014. doi: 10.1155/2014/939378

Svoboda, K. K., and Reenstra, W. R. (2002). Approaches to studying cellular signaling: a primer for morphologists. Anat. Rec. 269, 123-139. doi: 10.1002/ar.10074

Tabernero, J., Shapiro, G. I., LoRusso, P. M., Cervantes, A., Schwartz, G. K., Weiss, G. J., et al. (2013). First-in-humans trial of an RNA interference therapeutic targeting VEGF and KSP in cancer patients with liver involvement. Cancer Discov. 3, 406-417. doi: 10.1158/2159-8290.CD-12-0429

Tahaghoghi-Hajghorbani, S., Zafari, P., Masoumi, E., Rajabinejad, M., Jafari-Shakib, R., Hasani, B., et al. (2020). The role of dysregulated immune responses in COVID-19 pathogenesis. Virus Res. 290:198197. doi: 10.1016/j.virusres.2020.198197

Talebian, S., and Conde, J. (2020). Why go NANO on COVID-19 pandemic? Matter 3, 598-601. doi: 10.1016/j.matt.2020.08.005

Tang, Z., Zhang, X., Shu, Y., Guo, M., Zhang, H., and Tao, W. (2021). Insights from nanotechnology in COVID-19 treatment. Nano Today 36:101019. doi: 10.1016/j.nantod.2020.101019

Tay, M. Z., Poh, C. M., Rénia, L., MacAry, P. A., and Ng, L. F. P. (2020). The trinity of COVID-19: immunity, inflammation and intervention. Nat. Rev. Immunol. 20, 363-374. doi: 10.1038/s41577-020-0311-8

Tekade, R. K., Maheshwari, R., Soni, N., Tekade, M., and Chougule, M. B. (2017). "Nanotechnology for the development of nanomedicine," in NanotechnologyBased Approaches for Targeting and Delivery of Drugs and Genes, eds V. Mishra, P. Kesharwani, M. C. I. M. Amin, and A. Iyer (Cambridge, MA: Academic Press), 3-61.

Temgoua, M. N., Endomba, F. T., Nkeck, J. R., Kenfack, G. U., Tochie, J. N., and Essouma, M. (2020). Coronavirus disease 2019 (COVID-19) as a multisystemic disease and its impact in low- and middle-income countries (LMICs). SN Compr. Clin. Med. 20:1-11. doi: 10.1007/s42399-020-00417-7

Teuwen, L. A., Geldhof, V., Pasut, A., and Carmeliet, P. (2020). COVID19: the vasculature unleashed. Nat. Rev. Immunol. 20, 389-391. doi: $10.1038 /$ s41577-020-0343-0

The Lancet Haematology (2020). COVID-19 coagulopathy: an evolving story. Lancet Haematol. 7:e425. doi: 10.1016/S2352-3026(20)30151-4

Thompson, J. M., and Iwasaki, A. (2008). Toll-like receptors regulation of viral infection and disease. Adv. Drug Deliv. Rev. 60, 786-794. doi: 10.1016/j.addr.2007.11.003

Tiwari, A., Saraf, S., Verma, A., Panda, P. K., and Jain, S. K. (2018). Novel targeting approaches and signaling pathways of colorectal cancer: an insight. World J. Gastroenterol. 24, 4428-4435. doi: 10.3748/wjg.v24.i39.4428

Tran, M. A., Smith, C. D., Kester, M., and Robertson, G. P. (2008). Combining nanoliposomal ceramide with sorafenib synergistically inhibits melanoma and breast cancer cell survival to decrease tumor development. Clin. Cancer Res. 14, 3571-3581. doi: 10.1158/1078-0432.CCR-07-4881

Tsai, Y. S., Chen, Y. H., Cheng, P. C., Tsai, H. T., Shiau, A. L., Tzai, T. S., et al. (2013). TGF- $\beta 1$ conjugated to gold nanoparticles results in protein conformational changes and attenuates the biological function. Small 9,2119-2128. doi: 10.1002/smll.201202755 
Turk, C., Turk, S., Malkan, U. Y., and Haznedaroglu, I. C. (2020a). Three critical clinicobiological phases of the human SARS-associated coronavirus infections. Eur. Rev. Med. Pharmacol. Sci. 24, 8606-8620. doi: 10.26355/eurrev_202008_22660

Turk, C., Turk, S., Temirci, E. S., Malkan, U. Y., and Haznedaroglu, I. C. (2020b). In vitro analysis of the renin-angiotensin system and inflammatory gene transcripts in human bronchial epithelial cells after infection with severe acute respiratory syndrome coronavirus. J. Renin. Angiotensin Aldosterone Syst. 21:1470320320928872. doi: 10.1177/14703203209 28872

Turkia, M. (2020). COVID-19, Vascular Endothelial Growth Factor (VEGF) and Iodide. doi: $10.2139 /$ ssrn.3604987

Tyagi, PK., Tyagi, S., Kumar, A., Ahuja, A., and Gola, D. (2021). Contribution of nanotechnology in the fight against COVID-19. Biointerface Res. Appl. Chem. 11, 8233-8241. doi: 10.33263/BRIAC111.82338241

U.S. Food and Drug Administration. (2020) FDA Cautions Against the Use of Hydroxychloroquine or Chloroquine for COVID-19 Outside of the Hospital Setting or a Clinical Trial Due to Risk of Heart Rhythm Problems. Available online at: https://www.fda.gov/drugs/drug-safety-and-availability/fdacautions-against-use-hydroxychloroquine-or-chloroquine-covid-19- outsidehospital-setting-or (accessed July 09, 2020).

Uckun, F. M., Dibirdik, I., Qazi, S., and Yiv, S. (2010). Therapeutic nanoparticle constructs of a JAK3 tyrosine kinase inhibitor against human B-lineage ALL cells. Arzneimittelforschung 60, 210-217. doi: 10.1055/s-0031-1296275

van Eeden, C., Khan, L., Osman, M. S., and Tervaert, J. W. C. (2020). Natural killer cell dysfunction and its role in COVID-19. Int. J. Mol. Sci. 21:6351. doi: $10.3390 /$ ijms 21176351

van Putten, J. P. M., and Strijbis, K. (2017). Transmembrane mucins: signaling receptors at the intersection of inflammation and cancer. J. Innate Immun. 9, 281-299. doi: 10.1159/000453594

Varchetta, S., Mele, D., Oliviero, B., Mantovani, S., Ludovisi, S., Cerino, A., et al. (2020). Unique immunological profile in patients with COVID-19. Cell Mol Immunol. 18, 604-612. doi: 10.1038/s41423-020-00557-9

Velavan, T. P., and Meyer, C. G. (2020). The COVID-19 epidemic. Trop. Med. Int. Health 25, 278-280. doi: 10.1111/tmi.13383

Ventola, C. L. (2012). The nanomedicine revolution: part 1: emerging concepts. $P$ T. 37, 512-525.

Voynow, J. A., and Rubin, B. K. (2009). Mucins, mucus, and sputum. Chest 135, 505-512. doi: 10.1378/chest.08-0412

Wang, C., Xie, J., Zhao, L., Fei, X., Zhang, H., Tan, Y., et al. (2020a). Alveolar macrophage dysfunction and cytokine storm in the pathogenesis of two severe COVID-19 patients. EBioMedicine 57:102833. doi: 10.1016/j.ebiom.2020.102833

Wang, I. J., Wu, C. Y., and Hu, F. R. (2007). Effect of proinflammatory cytokines on the human MUC5AC promoter activity in vitro and in vivo. Clin Ophthalmol. $1,71-77$.

Wang, J., Li, Q., Yin, Y., Zhang, Y., Cao, Y., Lin, X., et al. (2020b). Excessive neutrophils and neutrophil extracellular traps in COVID-19. Front. Immunol. 11:2063. doi: 10.3389/fimmu.2020.02063

Wang, T. H., Chan, Y. H., Chen, C. W., Kung, W. H., Lee, Y. S., Wang, S. T., et al. (2006). Paclitaxel (Taxol) upregulates expression of functional interleukin-6 in human ovarian cancer cells through multiple signaling pathways. Oncogene 25, 4857-4866. doi: 10.1038/sj.onc.1209498

Wehbe, Z., Hammoud, S., Soudani, N., Zaraket, H., El-Yazbi, A., and Eid, A. H. (2020). Molecular insights into SARS COV-2 interaction with cardiovascular disease: role of RAAS and MAPK signaling. Front. Pharmacol. 11:836. doi: $10.3389 /$ fphar.2020.00836

Wei, L-l., Wang, W-j., Chen, D-x., and Xu, B. (2020). Dysregulation of the immune response affects the outcome of critical COVID-19 patients. J. Med. Virol. 92, 2768-2776. doi: $10.1002 / \mathrm{jmv} .26181$

Weiss, C., Carriere, M., Fusco, L., Capua, I., Regla-Nava, J. A., Pasquali, M., et al. (2020). Toward nanotechnology-enabled approaches against the COVID-19 pandemic. ACS Nano 14, 6383-6406. doi: 10.1021/acsnano. 0c03697

World Health Organization (2020a). Coronavirus Disease (COVID-19): Similarities and Differences With Influenza. Available online at: https://www.who.int/news$\mathrm{room} / \mathrm{q}$-a-detail/coronavirus-disease-covid-19-similarities-and-differenceswith-influenza (accessed November 24, 2020).
World Health Organization (2020b). Coronavirus Disease 2019 (COVID-19) Pandemic. Available online at: https://www.who.int/emergencies/diseases/ novel-coronavirus-2019 (accessed December 19, 2020).

World Health Organization (2020c). COVID-19- Landscape of Novel Coronavirus Candidate Vaccine Development Worldwide. Available online at: https://covid19.who.int/? gclid=CjwKCAiApNSABhAlEiwANuR9YM0k0JigJ56NivXbxLo GNuUC2W0j79EBV9ZLho5WBFDR7AO8Bt2ihoCqfoQAvD_BwE (accessed February 24, 2020).

World Health Organization (2020d). COVID-19 Vaccines. Available online at: https://www.who.int/emergencies/diseases/novel-coronavirus-2019/covid19-vaccines (accessed February 24, 2020).

World Health Organization (2020e). Transmission of SARS-CoV-2: Implications for Infection Prevention Precautions. Available online at: https://www.who.int/ news-room/commentaries/detail/transmission-of-sars-cov-2-implicationsfor-infection-prevention-precautions: :text=Current $\% 20$ evidence \%20suggests\%20that\%20transmission,\%2C\%20talks\%20or\%20sings (accessed on December 7, 2020).

World Health Organization (2020f). WHO Coronavirus Disease 2019 (COVID-19) Dashboard. Available online at: https://covid19.who.int/ (accessed February 26, 2021).

World Health Organization (2020g). WHO Director-General's Opening Remarks at the Media Briefing on COVID-19- 20 November 2020. Available online at: https://www.who.int/director-general/speeches/detail/who-director-generals-opening-remarks-at-the-media-briefing-on-covid-19-\$-\$20-november2020 (accessed November 24, 2020).

Wrana, J. L. (2013). Signaling by the TGF $\beta$ superfamily. Cold Spring Harb. Perspect. Biol. 5:a011197. doi: 10.1101/cshperspect.a011197

Wu, J., Ivanov, A. I., Fisher, P. B., and Fu, Z. (2016). Polo-like kinase 1 induces epithelial-to-mesenchymal transition and promotes epithelial cell motility by activating CRAF/ERK signaling. Elife. 5:e10734. doi: 10.7554/eLife.10734

Xia, Q. D., Xun, Y., Lu, J. L., Lu, Y. C., Yang, Y. Y., Zhou, P., et al. (2020). Network pharmacology and molecular docking analyses on Lianhua Qingwen capsule indicate Akt1 is a potential target to treat and prevent COVID-19. Cell Prolif. 53:e12949. doi: 10.1111/cpr.12949

Xia, Y., Cai, P., Yu, F., Xiong, L., He, X. L., Rao, S. S., et al. (2017). IL-4-induced caveolin-1-containing lipid rafts aggregation contributes to MUC5AC synthesis in bronchial epithelial cells. Respir Res. 18:174. doi: 10.1186/s12931-017-0657-z

Xie, Y., Shi, X., Sheng, K., Han, G., Li, W., Zhao, Q., et al. (2019). PI3K/Akt signaling transduction pathway, erythropoiesis and glycolysis in hypoxia (review). Mol. Med. Rep. 19, 783-791. doi: 10.3892/mmr.2018.9713

$\mathrm{Xu}, \mathrm{W}$., Zhao, T., and Xiao, H. (2020). The implication of oxidative stress and AMPK-Nrf2 antioxidative signaling in pneumonia pathogenesis. Front. Endocrinol. 11:400. doi: 10.3389/fendo.2020.00400

Xu, Y., Wen, Z., and Xu, Z. (2009). Chitosan nanoparticles inhibit the growth of human hepatocellular carcinoma xenografts through an antiangiogenic mechanism. Anticancer Res. 29, 5103-5109.

Xu, Z., Wang, Y., Zhang, L., and Huang, L. (2014). Nanoparticle-delivered transforming growth factor- $\beta$ siRNA enhances vaccination against advanced melanoma by modifying tumor microenvironment. ACS Nano 8, 3636-3645. doi: 10.1021/nn500216y

Xue, X., Wang, L. R., Sato, Y., Jiang, Y., Berg, M., Yang, D. S., et al. (2014). Singlewalled carbon nanotubes alleviate autophagic/lysosomal defects in primary glia from a mouse model of Alzheimer's disease. Nano Lett. 14, 5110-5117. doi: $10.1021 / \mathrm{nl} 501839 \mathrm{q}$

Yallapu, M. M., Maher, D. M., Sundram, V., Bell, M. C., Jaggi, M., and Chauhan, S. C. (2010). Curcumin induces chemo/radio-sensitization in ovarian cancer cells and curcumin nanoparticles inhibit ovarian cancer cell growth. J. Ovarian Res. 3:11. doi: 10.1186/1757-2215-3-11

Yang, H., Fung, S. Y., and Liu, M. (2011). Programming the cellular uptake of physiologically stable peptide-gold nanoparticle hybrids with single amino acids. Angew. Chem. Int. Ed. Engl. 50, 9643-9646. doi: 10.1002/anie.201102911

Yang, H., Fung, S. Y., Xu, S., Sutherland, D. P., Kollmann, T. R., Liu, M., et al. (2015). Amino acid-dependent attenuation of toll-like receptor signaling by peptide-gold nanoparticle hybrids. ACS Nano 9, 6774-6784. doi: $10.1021 / \mathrm{nn} 505634 \mathrm{~h}$

Yang, H., Kozicky, L., Saferali, A., Fung, S. Y., Afacan, N., Cai, B., et al. (2016). Endosomal $\mathrm{pH}$ modulation by peptide-gold nanoparticle hybrids enables 
potent anti-inflammatory activity in phagocytic immune cells. Biomaterials 111, 90-102. doi: 10.1016/j.biomaterials.2016.09.032

Yang, H., Zhou, Y., Fung, S.-Y., Wu, L., Tsai, K., Tan, R., et al. (2013). Amino acid structure determines the immune responses generated by peptide-gold nanoparticle hybrids. Part. Part. Syst. Charact. 30, 1039-1043. doi: 10.1002/ppsc.201300213

Yang, L., Liu, S., Liu, J., Zhang, Z., Wan, X., Huang, B., et al. (2020). COVID-19: immunopathogenesis and Immunotherapeutics. Signal Transduct. Target Ther. 5:128. doi: 10.1038/s41392-020-00243-2

Yaqoob, A. A., Ahmad, H., Parveen, T., Ahmad, A., Oves, M., Ismail, I. M. I., et al. (2020). Recent advances in metal decorated nanomaterials and their various biological applications: a review. Front. Chem. 8:341. doi: $10.3389 /$ fchem.2020.00341

Yarmohammadi, A., Yarmohammadi, M., Fakhri, S., and Khanm, H. (2020). Targeting pivotal inflammatory pathways in COVID-19: a mechanistic review. Eur. J. Pharmacol. 890:173620. doi: 10.1016/j.ejphar.2020. 173620

Yuki, K., Fujiogi, M., and Koutsogiannaki, S. (2020). COVID-19 pathophysiology: a review. Clin. Immunol. 215:108427. doi: 10.1016/j.clim.2020. 108427

Zhang, Q., Honko, A., Zhou, J., Gong, H., Downs, S. N., Vasquez, J. H., et al. (2020). Cellular nanosponges inhibit SARS-CoV-2 infectivity. Nano Lett. 20, 5570-5574. doi: 10.1021/acs.nanolett.0c02278

Zhang, X., Yin, H., Li, Z., Zhang, T., and Yang, Z. (2016). Nano-TiO 2 induces autophagy to protect against cell death through antioxidative mechanism in podocytes. Cell Biol. Toxicol. 32, 513-527. doi: 10.1007/s10565-016-9 352-y

Zhang, Y., Wang, Z., Zhang, Y., Tong, H., Zhang, Y., and Lu, T. (2020). Potential mechanisms for traditional Chinese medicine in treating airway mucus hypersecretion associated with coronavirus disease 2019. Front. Mol. Biosci. 7:577285. doi: 10.3389/fmolb.2020.577285

Zheng, M., Gao, Y., Wang, G., Song, G., Liu, S., Sun, D., et al. (2020). Functional exhaustion of antiviral lymphocytes in COVID-19 patients. Cell Mol Immunol. 17, 533-535. doi: 10.1038/s41423-020-0402-2

Zheng, Y., Li, R., and Liu, S. (2020). Immunoregulation with mTOR inhibitors to prevent COVID-19 severity: a novel intervention strategy beyond vaccines and specific antiviral medicines. J. Med. Virol. 92, 1495-1500. doi: 10.1002/jmv.26009

Conflict of Interest: The authors declare that the research was conducted in the absence of any commercial or financial relationships that could be construed as a potential conflict of interest.

Copyright (C) 2021 Peter, Sandeep, Rao and Kalpana. This is an open-access article distributed under the terms of the Creative Commons Attribution License (CC BY).

The use, distribution or reproduction in other forums is permitted, provided the original author(s) and the copyright owner(s) are credited and that the original publication in this journal is cited, in accordance with accepted academic practice. No use, distribution or reproduction is permitted which does not comply with these terms. 


\section{GLOSSARY}

\begin{tabular}{|c|c|}
\hline ACE & Angiotensin-converting enzyme \\
\hline ADE & Antibody-dependent enhancement \\
\hline AkT/PKB & Protein kinase B \\
\hline ALT & Alanine transaminase \\
\hline AMPK & AMP-activated protein kinase \\
\hline AST & Aspartate aminotransferase \\
\hline ARDS & Acute respiratory distress syndrome \\
\hline $\mathrm{CCL}$ & Chemokine ligands \\
\hline CD & Cluster of differentiation \\
\hline CKD & Chronic kidney disease \\
\hline COPD & Chronic obstructive pulmonary disease \\
\hline COVID-19 & Coronavirus disease 2019 \\
\hline CRP & C-reactive protein \\
\hline CVA & Cerebrovascular accident \\
\hline CVD & Cardiovascular disease \\
\hline $\mathrm{CXCL}$ & Chemokine ligand (C-X-C motif) \\
\hline DC & Dendritic cell \\
\hline ERK & Extracellular-signal-regulated kinase \\
\hline ESR & Erythrocyte sedimentation rate \\
\hline FITC & Fluorescein isothiocyanate \\
\hline G-CSF & Granulocyte colony-stimulating factor \\
\hline Gl & Gastrointestinal \\
\hline GM-CSF & Granulocyte-macrophage colony-stimulating factor \\
\hline $\mathrm{HCC}$ & Human hepatocellular carcinoma \\
\hline HDL & High density lipoprotein \\
\hline HGF & Hepatocyte Growth Factor \\
\hline hnRNA & Heterogeneous nuclear RNA \\
\hline IFN & Interferon \\
\hline IL & Interleukin \\
\hline IP & Interferon gamma-induced protein \\
\hline IRF & Interferon regulatory transcription factor \\
\hline ISG & Interferon-stimulated gene \\
\hline ISRE & IFN-stimulated response element \\
\hline JAK & Janus kinase \\
\hline LCP & Lipid-calcium-phosphate \\
\hline $\mathrm{LDH}$ & Lactate dehydrogenase \\
\hline LPH & Liposome-protamine-hyaluronic acid \\
\hline LPS & Lipopolysaccharides \\
\hline LT & Lymphotoxin \\
\hline LUV & Large unilamellar vesicle \\
\hline MAPK & Mitogen activated protein kinase \\
\hline MCP & Monocyte chemotactic protein \\
\hline M-CSF & Macrophage colony-stimulating factor \\
\hline MDA5 & Melanoma differentiation-associated protein 5 \\
\hline MD2 & Myeloid differentiation factor 2 \\
\hline MIP & Macrophage inflammatory proteins \\
\hline mTOR & Mammalian target of rapamycin \\
\hline MyD88 & Myeloid differentiation primary response 88 \\
\hline Nrf2 & Nuclear factor erythroid-2-related factor 2 \\
\hline NF-кB & Nuclear factor kappa light chain enhancer of activated B cell \\
\hline
\end{tabular}

$N P$

NRP

PAl

PAMP

PBMC

PCT

PEG

PEI

PGF

$\mathrm{PHB}$

PI3K

PLGA

PMMA

PTL

RBD

R\&D

RIG

SARS-CoV-2

SiRNA

SLN

STAT

TGF $\beta$

TLR

TNF

TRIF

TYK

VEGF
Natural Institutes of Health

Natural killer

Nanostructured lipid carriers

Nod-like receptor

NLR family pyrin domain containing 3

Nanoparticle(s)

Neuropilin

Plasminogen activator inhibitor

Pathogen-associated molecular pattern

Peripheral blood mononuclear cells

Procalcitonin

Polyethylene glycol

Polyethylenimine

Placenta growth factor

Poly- $\beta$-hydroxybutyrate

Phosphoinositide 3-kinase

Poly(lactic-co-glycolic acid)

Polymethyl methacrylate resin

Parthenolide

Receptor binding domain

Research and Development

Retinoic acid-inducible gene I

Severe acute respiratory syndrome coronavirus 2

Small interfering RNA

Solid lipid nanoparticles

Signal transducer and activation of transcription

Transforming growth factor beta

Toll-like receptor

Tumor necrosis factor

TIR-domain-containing adapter-inducing interferon- $\beta$

Tyrosine kinase

Vascular endothelial growth factor. 